\title{
LA PERSPECTIVA CATALANO-ARAGONESA DE D. JAIME DE SICILIA
}

\author{
Miguel MARZAL GARCÍA-QUISMONDO
}

El largo reinado de Jaime II, hueiga reiterarlo, es sumamente rico en cambios y proyectos. También es muy fecundo en las relaciones externas de la confederación catalano-aragonesa.

Esta riqueza, por supuesto, viene fomentada por la coyuntura que vive Jaime II en el gozne del difícil siglo XIV, pero, en última instancia, es el monarca quien imprime el ritmo a su reinado en respuesta a los retos internacionales. Pretendemos, pues, confirmar cómo su fino instinto político maduró durante su reinado en Sicilia dotándole un olfato político siciliano, una habilidad diplomática italiana y una concepción global mediterránea en el escenario hispánico. Aún más, supo ver en el reinado de Alfonso III, si bien en negativo desde su perspectiva siciliana, un experimento para definir sin riesgos sus propias directrices exteriores.

\section{LOS CONDICIONANTES DE LA EXPERIENCIA POLÍTICA DE D. JAIME}

La formación política de D. Jaime, muy temprana, tuvo en nuestra opinión cuatro referentes definitorios:

\subsection{El expansionismo mediterráneo}

Vocación ya enraizada en la casa de Barcelona en el último cuarto del siglo XIII y asumida en sus proyectos políticos.

Durante un tiempo se pensó que la casa de Barcelona no hacía sino secundar los 
intereses de los mercaderes barceloneses ${ }^{1}$, que habrían gestado un auténtico «imperialismo" a cuyo servicio estaría la Corona ${ }^{2}$. Nuevos documentos, un análisis más profundo y un nuevo enfoque metodológico han alterado completamente esta visión. Desde la comprobación de que los mercaderes barceloneses fueron el soporte y no la inspiración del expansionismo mediterráneo de los monarcas catalano-aragoneses ${ }^{3}$, lo que justifica entre ellos el protagonismo de los armadores sobre los mercaderes ${ }^{4}$, hasta reconocer una simbiosis entre la Corona y la nobleza urbana barcelonesa ${ }^{5}$, en que los monarcas respetaron los intereses de los mercaderes como medio para engrandecer la dinastía ${ }^{6}$, se llegó a la afirmación de que la propia complejidad de la confederación catalano-aragonesa explicaba un complicado expansionismo, en el que, empero, primó el particularismo dinástico ${ }^{7}$, que se yuxtapuso y superó a los intereses económicos ${ }^{8}$.

J. Lalinde Abadía reconoce ${ }^{9}$ que el expansionismo mediterráneo es personal, dinástico y feudal, complejo por los variados intereses que debió integrar la Corona, inscrito en las tensiones güelfo-gibelinas, con cierta participación de la nobleza e incorporación de la burguesia barcelonesa. En efecto, en nuestras propias investigaciones $^{10}$, vemos actuar a Pedro III estimulado por criterios feudales y dinásticos (los eco-

1 Variados han sido los análisis los análisis sobre el «despegue» de Barcelona, pero especialmente brillante la tesis de J.E. RUIZ DOMÉNEC, «La sociedad barcelonesa en los siglos XI y XII» y su artículo "El origen del capital comercial de Barcelona», Miscellanea Barcinonensia, XXXI, (1972), pp. 55-88. Existe un importante elenco historiográfico sobre la progresión, artículos, escenarios, caracteres de este comercio.

2 Tesis de R.S. LÓPEZ, desarrollada por J. Vicens Vives y articulada en el artículo, en colaboración con L. Suárez Fernández y C. Carrére, "La Economía en los Países de la Corona de Aragón en la Baja Edad Media", VI CHCA, ed. Madrid, 1959, pp. 103-135, en su opinión la "ruta africana" fue la columna vertebral de la expansión.

3 Cit. Y. RENOUARD, "Les principaux aspects économiques et sociaux de l'Histoire des pays de la Couronne d'Aragon aux Xlle, XIIle, XIVe siécles", VII CHCA, 1962, pp. 231-264.

4 Este protagonismo acentuó el carácter político del expansionismo, M. del TREPPO, "L'espansione catalano-aragonese nel Mediterraneo", en Nuove questioni di storia medievale, pp. 259-300, Milán, 1969.

5 F. UDINA MARTORELL, «La expansión mediterránea catalano-aragonesa», pp. 206-224, /l Congreso Internacional de Estudios sobre culturas del Mediterráneo Occidental, ed. 1978, distinguió entre «expansión comercial», sostenida por mercaderes y «expansión marítima» promovida por la Corona y la nobleza urbana, que proporcionó los grandes consejeros de Pedro III.

6 V. SALAVERT, "Nuevamente sobre la expansión mediterránea de la corona de Aragón», pp. 359-388, / Congreso..., cit. El autor señala Mạtjorca y Sicilia como prototipos de "reconquista» y «gloria».

7 Cit. G. PISTARINO, «Espansione mediterranea della Corona d'Aragona», pp. 193-207, II Congreso..., cit. Distinguía, además, entre objetivos dinástico-feudales, político-territoriales y económicomercantiles.

8 Afirma J.N. HILLGARTH, «El problema del Imperio catalano-aragonés», AEM, X, (1980), pp. 146-159.

9 La Corona de Aragón en el Mediterráneo Medieval (1229-1479), Zaragoza, 1979.

10 Mi propia Tesis inédita, Proyección de las Vísperas Sicilianas en la política peninsular española, 1282-1291. 
nómicos, meros coadyuvantes), en los que su hijo, el infante D. Jaime comprendió ser una pieza más.

\subsection{Las circunstancias dinásticas}

La fragilidad de la sucesión en los tronos hispánicos se había hecho patente por las arbitrarias y patrimonialistas disposiciones de Jaime I en Aragón, coincidiendo alarmantemente con el temible dilema sucesorio que las reformas legislativas de Alfonso X habían planteado en Castilla ${ }^{11}$. La actitud de Pedro III de Aragón, contradictoria, no ayudó: siendo infante obligó a su padre, Jaime I, el 20 de noviembre de 1275, reconocer a su primogénito $D$. Alfonso como heredero en caso de mori ${ }^{12}$, instaurando el derecho de representación como en las Partidas; luego, ya rey, en su testamento del 3 de junio de $1282^{13}$, refrendaba la "costumbre de España», esto es, la herencia consecutiva de los hijos varones en vida del rey. Pedro III, pues, nombraba su heredero al infante D. Alfonso y, en caso de morir, a su segundogénito el infante $D$. Jaime. Este testamento, en pleno ejercicio de soberanía, tendría una insospechada relevancia legal.

Desde entonces, dos circunstancias determinaron la situación dinástica del infante D. Jaime:

1ํ La supeditación dinástica a la rama agnaticia, siguiendo las pautas del vasallaje practicado por Jaime II de Mallorca ante su hermano Pedro en 1279 y convirtiéndose D. Jaime en el garante de la sucesoria "costumbre de España», en su calidad de segundogénito. La política de Pedro III para el dominio efectivo del Sistema Ibérico iba a ser una muestra. Viuda la señora de Molina, $D^{a}$ Blanca, y como única heredera su hija $\mathrm{D}^{\mathrm{a}}$ Isabel, desde 1281 el monarca aragonés proponía un matrimonio con uno de sus hijos para incluir el señorío molinés en la órbita aragonesa. En enero de 1282 $D^{\mathrm{a}}$ Blanca pareció aceptar ${ }^{14}$. Se iniciaron unas negociaciones culminadas el $20 \mathrm{de}^{\mathrm{abri}} \mathrm{1}^{15}$, en que Molina aceptó el matrimonio con el infante D. Fadrique, la alianza y casi protectorado aragonés. Deliberadamente se posponía a D. Jaime, llamado a una posible sucesión y que podía despertar una violenta reacción en Castilla.

La situación varió radicalmente cuando $\mathrm{D}$. Jaime se convirtió en corregente de Sicilia, lejana para las suspicacias castellanas. Muy ajeno a sus intereses sicilianos D. Jaime

11 Fragilidad analizada por R. GILBERT, «La sucesión al trono en la Monarquía española», Recueils de la Societé Jean Bodin pour l'Histoire comparative des Institutions, XXI, (1969), pp. 447-546.

12 Reg. J.E. MARTÍNEZ FERRANDO, “Índice cronológico de la colección de documentos inéditos del ACA», DGAB, XLII, (1973), p. 88. El 21 de noviembre las Cortes juraban a D. Alfonso.

13 Cit. R. ANDRÉS, Relación de testamentos..., p. 39, pero un estudio más profundo se encuentra en M. DUAL DE SERRANO, «Testamento de Soberanos medievales en el Archivo Real de Valencia», EEMCA, IV, (1951), pp. 436-446.

14 El 18 de enero Pedro III ordenó sufragar los vestidos de Domingo Pérez, embajador de Molina. ACA, Reg. 52, f. 1 v.

15 Ese día el rey de Aragón ratificó todos los compromisos pactados por sus embajadores con Da Blanca, ACA, Reg. 44, f. 228 V. 
se avenía dócilmente a la tortuosa política paterna en el sistema lbérico. El 21 de junio de 1283 Pedro III notificaba a $D^{a}$ Blanca que $D$. Jaime había dado plenos poderes al comendador de Alcañiz sobre un asunto «que ella conoce», ¿el proyectado matrimonio? D. Jaime se contempla como una pieza de la diplomacia aragonesa.

$2^{2}$ La ilegitimación de la dinastía aragonesa. La conquista de Sicilia provocó la excomunión de Pedro III por el Papa Martín IV el 18 de noviembre de 1282. Sin embargo, el Papa reservó todo el rigor de su poder hasta coordinar la estrategia con Carlos I de Anjou el 9 de marzo de 1283 en Viterbo ${ }^{16}$, en la que Francia era fundamental. Martín IV se comprometió a utilizar las terribles sanciones espirituales.

El 21 de marzo el Papa fulminó la bula «De insurgentis in» por la que condenaba a Pedro Ill y su dinastía, le priva de sus reinos, libera a sus súbditos de la obediencia y homenaje debidos y somete a sus estados al entredicho ${ }^{17}$, sentencia reiterada en bulas del 15 de abril y 27 de mayo siguientes. Era una seria amenaza por la infeudación de Aragón a la Santa Sede y la función de la Iglesia en la articulación de la comunidad política medieval. Consciente, Martín IV ofreció el trono aragonés a un hijo de Felipe III de Francia. El 1 de septiembre de 1283 el monarca francés declinaba, por cuanto un testamento regio legal había instituido legítimo heredero al infante D. Alfonso, aún, en el seno de la Iglesia ${ }^{18}$. Fulminante, ese día el Papa declaraba nula la donación de Pedro III a D. Alfonso ${ }^{19}$.

Era una arbitrariedad que Pedro III supo evidenciar con su escrupuloso respeto a las potestades pontificias ${ }^{20}$. Empero, incapaz incluso por la violencia de evitar la publicidad de las bulas pontificias, el monarca vio cómo exacerbaron la crisis latente por su estilo de gobierno y la empresa siciliana, desembocando en una rebelión de la que emanó en octubre de 1283 el Privilegio General y la Unión. Martín IV, entonces, confirmó las sanciones espirituales el 18 de noviembre de 1283 ilegitimando la dinastía aragonesa ${ }^{21}$.

Pedro III comprendió que debía erradicar una subversión tan peligrosa. En el invierno de 1283-84 la corte aragonesa halló en la escrupulosa argumentación legal francesa un arma jurídica insoslayable: el testamento del 3 de junio de 1282 era perfectamente legítimo, anterior a las sanciones y consolidaba como heredero de Aragón

16 Detalla S. RUNCIMAN, Las Visperas Sicilianas, Madrid, 1961, p. 234.

17 Regestada en varios catálogos, tan relevante bula que transcrita y publicada por F. OLIVIER MARTíN, Les Registres de Martín IV (1281-85), París, 1931-35, ํㅜ448, pp. 130-1.

18 Carta de clarificadora exposición de doctrina jurídica de monarca francés, reg. F.J. MIGUEL, Regesta de las letras pontificias del ACA, Madrid, 1984, nº 200, p. 112.

19 A.N. de France, j. 714-5. Reg. J. PAZ, Documentos relativos a España existente en los Archivos de Paris, Madrid, 1934, nº 149.

20 Estrategia estudiada por A. FÁBREGA GRAU, «Actitud de Pedro III el Grande de Aragón ante la propia deposición fulminada por el Papa Martín IV", Miscellanea Historiae Pontificae, XVIII, (1954), pp. 161-178.

21 Reg. A. POTTHOST, Regesta Pontificum Romanorum inde ab anno 1198 ad annum 1304, Berlin, 1875, no 22077, p. 1783; pub. F. OLIVIER MARTÍN, Les Registres de..., obr. cit., no 482, pp. 2202. Se dirigió a Venecia, Génova, Pisa, Ancona y «resto de las repúblicas marítimas» para cercenar la política mediterránea aragonesa. 
al infante D. Alfonso. Así se argumentó, con extrema habilidad, ante Felipe III de Francia, muy pundonoroso en cuanta a la dignidad y atribuciones de la institución monárquica. La maniobra tuvo éxito, porque Felipe III aceptó una controversia entre juristas franceses y aragoneses, fijada en Perpiñán para febrero de 1284 y destinada a dilucidar los derechos de D. Alfonso. A finales de enero, el infante aragonés nombraba sus defensores al obispo de Valencia D. Jazberto y a D. Pedro costa, su juez y consejero. La controversia, se inició el 11 de febrero ${ }^{22}$. Complementariamente, el infante facultaba a D. Artaldo de Rexach y D. Bernardo de Olorda para exponer sus derechos en la Santa Sede, con la plena cobertura de Pedro III $^{23}$.

La controversia, bien manipulada por juristas propapales, debió aplacar los escrúpulos de Felipe III: el 21 de febrero aceptaba la corona aragonesa para su hijo Cartos Valois Martín IV, satisfecho, refrendó las condenas a Pedro III el 6 de abril y $\mathbf{1 8}$ de mayo de 1284, incluso el 4 de junio ordenó predicar la cruzada contra el monarca aragonés y los sicilianos.

En realidad era una pirueta que de facto demostró la solidez de los derechos del infante D. Alfonso. Pedro III supo responder con otra pirueta: el 4 de octubre de 1284 D. Alfonso cedía sus derechos a su padre, Pedro $\mathrm{III}^{24}$, sorteando todos los anatemas pontificios. Una solemne embajada era enviada a Roma el 12 de diciembre para notificar al Papa sobre la nueva legalidad ${ }^{25}$. En todo caso la suerte dinástica de $D$. Jaime quedaba más unida y subordinada a sus hermano.

\subsection{Sicilia}

Centro de los circuitos comerciales más neurálgicos de la Cristiandad, base estratégica para cualquier proyecto de dominio mediterráneo, símbolo del «dominium» pontificio, era el escenario idóneo para el conflicto güelfo-gibelino. En ella D. Jaime pudo familiarizarse con la más alta política y pulsar la raíz de los intereses que palpitaban en el Mediterráneo. D. Jaime, además, pudo comprobar su débil posición en la tortuosa política siciliana, traducida en una mayor dependencia de Aragón. La experiencia de Pedro III fue reveladora.

22 El 1 de febrero, mediante carta al senescal de Carcasona citó a los juristas franceses el 11. El día 7 el infante dio plenos poderes a sus defensores y el 10 concedía dinero para la misión. Cit. del ACA las tres cartas de G. CARINI, Gli Archivi e le Biblioteche di Spagna, in rapporto alla Stotia d' Italia en generale e di Sicilia in particolare, II. Palermo, 1884, p. 164; J.E. MARTÍNEZ FERRANDO, Catálogo de los documentos del Antiguo Reino de Valencia, Madrid, 1934, ํㅡ 1857, 1860, 1861, pp. 397-8.

23 Cit. del ACA, G. CARINI, Ibídem, pp. 52-54 y 165-6. El 10 de febrero solicitó la asistencia legal de los más grandes juristas gibelinos italianos, especialmente de Raimundo de Ponte. El 13 de febrero advertía al papa sobre la llegada e intención de la legación.

24 Cit. G. CARINI, Ibídem, p. 173.

25 Seguridad diplomática al comendador franciscano y templario de Azcona y para el canónigo de Tudela Pedro Sánchez otorgada por Pedro III y solicitada al Papa. Ese día Pedro III les entregó credenciales ante el Papa, el colegio de Cardenales y los más destacados líderes gibelinos italianos. Otra vez solicitaba asistencia legal a Raimundo de Ponte y a los juristas gibelinos italianos. Seis documentos en el ACA, Reg. 47, f. 131 a 132 v. 
La conquista de Sicilia había sido fácil y rápida, pero sin entusiasmo siciliano, retraído por el republicanismo mesinés aspirante a una communitas Sicilial siguiendo el ejemplo italiano y por el recelo a un despotismo gibelino ${ }^{26}$. Las levas militares y exacciones fiscales para sostener la guerra, unido al asentamiento de catalanes y aragoneses en tierras confiscadas y su ocupación de los cargos político-administrativos relevantes, alimentaron una sorda resistencia a Pedro $\mathrm{II}^{27}$, que ni siquiera detuvo el Parlamento General de Catanía, donde el 25 de noviembre de 1282 se desmontó el impopular régimen fiscal angevino, ni la victoria naval de Nicotera en octubre.

Pedro III debió confiar sólo en el esfuerzo de sus estados hispánicos. Un eficaz infante D. Alfonso logró, desde el 10 de septiembre de 1282, organizar un sistema de convoyes que partía a Sicilia desde Barcelona y Valencia y que dirigían Cerviano de Narbona, Stefano de Seta, Marinone Lenguard y Ramón Calberto ${ }^{28}$.

Fue una medida prudente, porque desde octubre de 1282 crecían los "traidores", que llegaron a organizar una conspiración en enero de $1283^{29}$. Atizados por las bulas de perdón pontificias y el Parlamento de San Martín de D. Carlos de Salerno, heredero de Carlos I, una rebelión antiaragonesa estalló en marzo de 1283. Las fuerzas catalano-aragonesas se convirtieron en el pilar de todo el entramado de Pedro III en Sicilia. En marzo el infante D. Alfonso activó la construcción de una nuevo flota en las atarazanas de Barcelona y Valencia, mientras ordenaba a Cerviá de Riera reclutar soldados en Cataluña y a Ramón de Riusech en Valencia con destino a Sicilia ${ }^{30}$. Pedro III supo que debía volver a sus estados hispánicos para salvar la empresa siciliana, una experiencia bien asimilada por D. Jaime.

\subsection{La corregencia siciliana (1283-85)}

Pedro III sabía que anclar Sicilia en la órbita catalano-aragonesa iba a exigir una solución especial. Para ella optó por dos vías:

- Da Constanza, la Regina, legítima heredera de los Staufen sicilianos y a quien enseguida implicó el monarca aragonés en la política siciliana ${ }^{31}$. Finalmente, coinci-

26 Cit. M. AMARI, Guerra del Vespro Siciliano, reed. Palermo, 1973, pp. 239-42.

27 Política analizada por A. SCANDURA, "L'Espansionismo della Corona d'Aragona in Sicilia ai tempi di Pietro III il Grande», pp. 389-97, // Congreso Internacional de Estudios..., cit. en pp. 391-2.

28 Cit. documental de G. CARINI, Gli Archivi..., obr. cit., p. 133 y pub. G. LA MANTIA, Códice diplomático dei Re Aragonesi di Sicilia, 1282 a 1355, I. Palermo 1918, no 20. ACA, Reg. 59, f. 110.

29 Prisión de antiguos destacados líderes antiangevinos en las Vísperas, como Palmiero Abate, Simone Finetta, Ruggier di Maura, Gualterio Caltafione, incluso se sospechó de Alaimo de Lentini, cit. M. AMARI, Guerra del Vespro..., obr. cit., pp. 287-8.

30 ACA, Reg. 60 , f. 59 v, 60, 72, 92 v. Cit. parcialmente G. CARINI, Gli Archivi..., obr. cit. pp. 29 y 135-6; reg. parcialmente J.E. MARTÍNEZ FERRANDO, Catálogo del Antiguo..., II, obr. cit., no 1699, 1702, 1709, 1720, pp. 362-7; pub. parcialmente LA MANTIA, Códice diplomático dei..., obr. cit, oㅡ 24 y 25.

31 El 22 de octubre de 1282 el infante D. Alfonso ordenaba pagar vestidos al alfaquí Samuel, enviado por Pedro III a $D^{\mathrm{a}}$ Constanza, ACA Reg. 71, f. 224 v., reg. J.E. MARTINEZ FERRANDO, Catálogo del Antiguo..., II, obr. cit., no 1597, p. 340. El 28 de octubre Pedro III ordenó a Ramón Marquet 
diendo con las revueltas antiaragonesas de marzo de 1283, Ramón Marquet trasladó a principios de abril a $D^{\mathrm{a}}$ Constanza y los infantes $\mathrm{D}$. Jaime, D. Fadrique, $\mathrm{D}^{\mathrm{a}}$ Violante, desembarcados en Trápani. Era la conexión con la legitimidad Staufen.

- La corregencia y donación de reinos en vida, como hicieran los Capeto, antídoto contra la ilegitimación pontificia ${ }^{32}$. Al abandonar Aragón rumbo a Sicilia en 1282 Pedro III encargó la regencia al infante D. Alfonso y cuando el infante le cedió sus derechos el 4 de octubre de 1284, el 17 de noviembre el monarca le nombró Lugarteniente de Aragón, Valencia y Cataluña ${ }^{33}$.

El sistema se aplicó en Sicilia en torno a $\mathrm{D}^{\mathrm{a}}$ Constanza, como reverente legitimador. Ante el Parlamento en Mesina, el 19 de abril de $1283 \mathrm{D}^{\mathrm{a}}$ Constanza recibía la regencia, siendo heredero y corregente el infante $D$. Jaime ${ }^{34}$. La regencia supo generar una eficaz trama administrativa de catalano-aragoneses y sicilianos, mientras la seguridad, marítima y unida a Aragón se delegaba en Roger de Lauria el 20 de abril como Almirante de Cataluña y Sicilia ${ }^{35}$. Era un camino acertado: D: Jaime sofocó con energía la rebelión de Val de Noto en mayo de 1283 y Roger de Lauria derrotaba a la armada angevina en Malta el 8 de junio.

Sin embargo, el estilo de gobierno de Pedro III era de la más rancia estirpe gibelina: autoritario y centralizador. La Regencia debía reducirse a un testaferro cuya misión debía ser transformar la función de Sicilia: de receptora en dispensadora de recursos para sostener la política mediterránea del rey. Los documentos muestran la constante y directa intervención de Pedro III en Sicilia, con Giovanni Prócida como su «alter ego» ${ }^{36}$. D. Jaime y la Regencia carecieron de autonomía pero convirtieron Sicilia en la pieza útil que Pedro III precisaba, con tres funciones:

1 ํ Función táctica como frente militar subsidiario para aliviar la presión sobre Aragón, amenazado de invasión. Los intentos de Carlos I por invadir Sicilia se estrellaron con la gran victoria naval de Roger de Lauria en Nápoles (5 de junio de 1284), en la que apresaba a D. Carlos de Salerno, heredero de Carlos I. La iniciativa no solo pasó a

armar una galera para trasladar a $D^{\text {a }}$ Constanza y algunos de sus hijos a Sicilia, cit. F. SOLDAILA, L'Almirall Ramón Marquet, Barcelona, 1953, p. 26; el 4 de enero de 1283 D. Alfonso ordenaba unos pagos a tripulantes de naves de la Reina, ACA, Reg. 59, f. 191, reg. J.E. MARTÍNEZ FERRANDO, Ibídem, no 1639 , p. 350.

32 Junto con el testamento y jura en Cortes, en opinión de F. SOLDEVILA, «La pretensa donació dels regnes per Pere el Gran al sen fill Alfons", Homenaje a Vincke, ed. 1962-3, pp. 193-200.

33 ACA, Reg. 43, f. 66 v. Reg. J.E. MARTíNEZ FERRANDO, Catálogo del Antiguo..., obr. cit. no 2055, p. 439; pub. J. LALINDE ABADÍA, Gobernación General en la corona de Aragón, Zaragoza, 1963, nำ 2, pp. 501-2.

34 Junto con Giovanni Prócida como consejero plenipotenciario, vicario del Reino Guillén Galcerán y justicia Alaimo de Lentini. Bernard DESCLOT, Crónica, ed. M. Coll i Alentorn Barcelona, 1951, p. 202.

35 Se complace en la ceremonia R. MUNTANER, Crónica, reed. F. Soldevila, Barcelona, 1948, p. 117.

36 El 29 de julio de 1283 el monarca refrendaba todos los actos políticos de Prócida, pub. LA MANTIA, Códice diplomático dei..., obr. cit., $\mathrm{n}^{\circ} 30$, pp. 76-77. El 31 de enero lo convertía en Canciller vitalicio de Sicilia, ACA, Reg. 46, f. 160, pub. Ibídem, no 40, pp. 93-95. 
manos sículo-aragonesas (invaden Calabria), sino que el futuro de los estados angevinos quedaba hipotecado.

En la retaguardia D. Jaime aseguraba la adhesión siciliana. El infante continuó la inteligente política de incorporación de sicilianos a su administración ${ }^{37}$, confirmó la fidelidad de los maestres portulanos, maestre racional y los castillos a Pedro III. En agosto de 1285 hábilmente desmontó una conspiración antiaragonesa, que salpicó a Alaimo de Lentini.

$2^{\circ}$ Función logística, en la que destacó la competencia de D. Jaime. Desde agosto de 1283 parece iniciarse un circuito exportador de trigo entre Sicilia y Barcelona, secundado por La Regencia ${ }^{38}$ y al que D. Jaime incorporaba Mesina ${ }^{39}$. En 1284 Sicilia llegaba a proporcionar dinero a Aragón ${ }^{40}$. Cuando en 1285 se hacía inminente la temible invasión francesa en Aragón, Sicilia pudo aportar dos elementos imprescindibles: abastos y flota.

La fuerte concentración de tropas y las malas cosechas de 1285, provocaron en marzo-abril las revueltas de Barcelona, Gerona y Lérida. En mayo de 1285, Pedro III interrumpía el acarreo de trigo siciliano por particulares para centralizarlo en manos de Bernardo de Segalars ${ }^{41}$. D. Jaime sólo era informado de la orden el 3 de junio, otra muestra de escasa autonomía política.

Contra la armada francesa, Pedro III proyectó una flota defensiva en Cataluña comandada por Ramón Marquet y Berenguer Mallol, y otra ofensiva la siciliana de Roger de Lauria, reforzada con abastos ${ }^{42}$, tropas $^{43}$ y corsarios ${ }^{44}$. El 28 de agosto de 1285 Lauria hundía en Les Formigues la armada francesa y la invasión de Cataluña.

3 Función estratégica. La alta política que monopolizó Pedro III. Aún así desde Sicilia D. Jaime pudo constatar en primera línea las circunstancias de dos escenarios muy importantes.

37 A instancias del rey, D. Jaime recompensaba a Ugo Tallach y Perrone Caltagirone, el 4 de junio de 1284 con oficios en la corte. ACA, Reg. 46, f. 205. Pub. LA MANTIA, Ibídem, no 50, pp. 117-118.

38 El 9 de agosto Pedro III ordenaba permitir la exportación de trigo siciliano al catalán Geraldo de Rocha, ACA, Reg. 46, f. 99 v. El 17 de septiembre los regentes ordenaban a Roger de Lauria permitir la exportación de trigo siciliano. Pub. LA MANTIA, Ibídem, ํo 120, p. 542.

39 Confirmación por el infante de todos sus privilegios a Mesina. Pub. LA MANTIA, Ibídem, $n^{\circ} 38$, pp. 85-89.

40 El 9 de abril Pedro III ordenaba al baile de Barcelona custodiar el dinero procedente de Sicilia, Cit. G. GARINI, Gli Archivi..., obr. cit, p. 29.

41 Facultad concedida el 22 de mayo, ACA, Reg. 56, f. 105. El 21 de mayo el rey había permitido a una nave de Ramón Marquet partir a Sicilia, ACA, Reg. 56, f. 104, pero el día 22 le advirtió que comprase el trigo a Segalars, ACA, Reg. 56, f. 105.

42 Permiso real de exportación de pez para la armada siciliana, el 16 de abril, ACA, Reg. 56, f. 70. El 23 de junio se enviaban víveres y dinero, ACA, Reg. 58, f. 32 v.

43 Salvoconducto, el 30 de junio, a Pedro Íñiguez para ir a Sicilia, ACA, Reg. 57, f. 140.

44 Reavituallamiento para el corsario Attobono de Trápani y compañeros el 5 de mayo, ACA, Reg. 58, f. 23. El 28 de mayo una nave de Marquet transportaba marinería a Sicilia, ACA, Reg. 56, f. $104 \mathrm{v}$. El 23 de octubre el rey ordenó pagar 1400 onzas de oro a los corsarios que acudieron a Sicilia, ACA, Reg. 58, f. 81. 
- Génova, la potencia condicionante de todo el Mediterráneo. Las Vísperas Sicilianas habían acabado con el proyecto de un Imperio angevino de Marsella a Jerusalén (con Sicilia y Constantinopla) y Génova creyó llegado el momento de imponer "su imperialismo». En su consecución después del verano de 1282 se lanzó a una feroz contienda con Pisa. Pedro III comprendió toda la dimensión de tan colosal combate próximo a Sicilia e intentó la inhibición ${ }^{45}$. Empero, desde el 30 de agosto de 1283 Génova controlaba Cerdeá, estación en la ruta de Cataluña a Sicilia. Desde entonces, Pedro III inició un distanciamiento de Pisa ${ }^{46}$, paralelo a un aproximación a Génova: preocupando la controversia de Perpiñan, el 10 de febrero de 1284 informaba a los linajes genoveses sobre su legitimidad, en tanto que en mayo reconocía los derechos genoveses a exportar trigo siciliano y les dedicaba especial protección ${ }^{47}$.

Cuando la victoria de la Meloria (6 de agosto de 1284) Génova se deshizo de Pisa, sólo apuntaba como rival Barcelona. La consigna fue aplacar una potencia que determinará la política mediterránea aragonesa: el 17 de agosto de 1284 se concedía especial permiso exportador de trigo a los genoveses ${ }^{48}$, mientras el 24 de noviembre y el 19 de noviembre D. Jaime confirmaba los privilegios y exenciones de los genoveses en Sicilia.

- Túnez, Reino vasallo y tributario de el de Sicilia. Era un escenario que interesaba a Pedro III (expedición a Collo), pero una vez rey de Sicilia de nuevo los intereses económicos sostenían los derechos feudales. Desde agosto de 1283 Pedro III inició la intervención ${ }^{49}$, después de la victoria de Lauri en Malta. A pesar de que en julio de 1284 se coronaba como nuevo califa tunecino Abu Hafs, no hubo tampoco entendimiento ${ }^{50}$. Pedro III, entonces acudió a la presión militar (Lauria ocupa Djerba en octubre de 1284, Kerkennah en abril de 1285), la subversión aliándose con Tremecén en octubre de 1284 para oponer a Abu Zacariya contra Abu Hafs y a una alianza antitunecina con Granada, Marruecos y Tremecén. A fines de mayo de 1285 llegaban embajadores de Abu Hafs a Barcelona ${ }^{51}$. el 2 de junio firmaban el tratado de Panigars por el que, entre otros capítulos (ponduk, aduanas, milicias), reconocían a Pedro III rey de Sicilia y un tributo de 33.333 besantes anuales.

45 El 7 de abril de 1283 solicitaba la alianza de la gibelina Pisa, en tanto no implicase a Aragón en la contienda. Cit. C. TRASELLI, I privilegi di Mesina e di Trapani, Palermo, 1949, p. 40.

46 Airada protesta, el 30 de septiembre de 1283, por los ataques corsarios pisanos a mercaderes catalanes, ACA, Reg. 46, f. 110. Las protestas crecerán en meses posteriores.

47 El 7 de mayo ordenaba deponer al pisano Gerardo Bossi, justicia de Val di Mazzara, por perseguir a los genoveses, “amici carissimi» y «nostri especiales amici». ACA, Reg. 46, f. 192. Pub. LA MANTIA, Códice diplomático dei..., obr. cit., no 46, pp. 110-111.

48 ACA, Reg. 43, f. 22. El 7 de noviembre se recordaba este permiso a Ramón de Sant Liceri.

49 El 9 de agosto desautoriza a dos galeras con trigo siciliano tocar Túnez con destino a Mallorca, ACA, Reg. 46, f. 104. Al tiempo, enviaba a Rodrigo Jiménez de Luna, que volvía en septiembre sin entendimiento pero con una nave de gran valor: ¿el tributo?

50 El 4 de noviembre Pedro III notificaba al vicario y baile de Barcelona como bienes de mercaderes catalanes habían sido requisados en Túnez por orden del nuevo Califa, ACA, Reg. 43, f. 55 v.

51 En cuatro cartas, entre el 25 de mayo y el 4 de junio, ACA, Reg. 58, f. 26 y 28 r y v. Pedro III ordenaba la manutención y traslado de estos embajadores. 


\subsection{La confederación dinástica}

Sicilia tenía un peso específico entre los estados de Pedro III, pues, que una Regencia reducida a mero testaferro no reconocía. Se multiplicaban las ansias de autonomismo: D. Jaime será el portavoz y D. Carlos de Salerno el instrumento.

Con cuidada aparatosidad una revuelta de linchamiento y una condena a muerte amenazaban al Príncipe de Salerno, preso en Montegrijón después de ser capturado en la batalla de Nápoles. Alarmado, enseguida Carlos I inició negociaciones con D. Jaime ${ }^{52}$. So pretexto de garantizar su seguridad D. Jaime trasladó al Príncipe de Salerno a Cefalú, donde le arrancaba un provechoso acuerdo: D. Jaime, D. Fadrique y D. Violante casarían con sendos hijos del Príncipe y serían reconocidos rey de Sicilia $e$ islas adyacentes, duque de Tarento y señora de Calabria respectivamente. como seguro D. Carlos entregaría en rehén tres de sus hijos, ciertos nobles provenzales, un rescate y prometía lograr la paz de Aragón con Francia y el Papado ${ }^{53}$. D. Jaime, así, generaba un orden apropiado en el sur italiano. Carlos I lo rechazó.

Los sucesos, entonces se precipitaron. el 7 de enero de 1285 moría Carlos I. Preso en Sicilia su heredero el Príncipe de Salerno, los estados angevinos parecieron desintegrarse. Sólo las enérgicas medidas de Martín IV, capaces de imponer un gobierno ${ }^{54}$, evitaron la hecatombe, pero el Papa eligió a Honorio IV el 2 de abril, un Savelii, aristocrática y güelfa familia romana. El nuevo Papa no decepcionó: el 31 de mayo de 1285 refutaba la legitimidad de D. Alfonso ${ }^{55}$. En bulas sucesivas otorgó apoyo financiero a la invasión de Cataluña y el 30 de julio ofreció absolución a los sicilianos que abandonasen la causa aragonesa.

Pedro III, ante la inminente invasión francesa, comprendió que debía solventar el encaje de Sicilia en la órbita catalano-aragonesa. El 3 de febrero de 1285 expidió cartas secretas a $D^{\text {a }}$ Constanza y $D$. Jaime ${ }^{56}$, cuyo resultado fue que el 12 de febrero $D$. Jaime jurara por heredero de Aragón al infante $\mathrm{D}$. Alfonso, le prestara homenaje y prometiera absoluto apoyo en la defensa de sus derechos ${ }^{57}$. En correspondencia, el 8 de mayo D. Alfonso reconocía la donación del Reino de Sicilia a D. Jaime ${ }^{58}$. No tardó D. Jaime en estrenar su mayor margen político: a pesar de los urgentes requerimientos de Pedro III el 29 y 31 de mayo para entregarle al Príncipe de Salerno. D. Jaime

52 Dos cartas de D. Jaime certifican que existían negociaciones con Carlos I. Pub. LA MANTIA, Códice diplomático dei..., nº 159-160, p. 352.

53 Refiere L. D'ARIENZO, «Documenti sulla prigionia di Carlos II d'Angio, Principe di Salerno», XI CHCA, II, pp. 489-555, ed. Palermo, 1983, p. 495.

54 El 16 de febrero imponía como regentes al conde de Artois y al cardenal de Santa Sabina, reconociendo futuro rey a D. Carlos de Tarento, primogénito del Príncipe de Salerno. Reg. A. POTTHOST, Regesta Pontificum..., obr. cit., no 22213, p. 1793.

55 Ordena retirar licencia a todo eclesiástico que sostuviese al infante A. N. Francia, j. 714-9, reg. J. PAZ, Documentos relativos a..., obr. cit., $\mathrm{n}^{\circ} 161$.

56 ACA, Reg. 58, f. 5. Pub. LA MANTIA, Códice diplomático dei..., obr. cit., nº 65.

57 Cit. G. CARINI, Gli Archivi..., obr. cit., p. 209.

58 ACA, Reg. 62, f. 152. Pub. LA MANTIA, Códice diplomático dei..., obr. cit., no 79, pp. 150-153. 
únicamente accede al contacto diplomático $0^{59}$ y sólo lo entrega cuando fue seguro el fracaso de la invasión francesa en Cataluña, en octubre de 1285. Sicilia, empero, se mantuvo firme en la adhesión a Aragón.

El estrepitoso fracaso de la invasión convenció a Honorio IV de dos cosas: convenía a la Santa Sede un estado italiano y dependiente como brazo de la Iglesia (estados angevinos) e italianizar al contencioso de las Vísperas (concentración en la recuperación de Sicilia). El Papa promulga disposiciones que alentasen a los sicilianos en el retorno a la obediencia angevina y pontificia, que culminaron el 17 de septiembre de 1285 con la «Constitución de Sicilia» reguladora de un estado angevino más eficaz y popular. El efecto fue fulminante, porque el sur italiano tornó de grado a la obediencia angevina. Era el umbral de la otra época.

Aragón también ayudó a traspasar ese umbral. Cuando preparaba la conquista de Mallorca, Pedro III enferma y, antes de morir, publica el 2 de noviembre de 1285 un nuevo testamento confirmando la división de Aragón, Valencia y Cataluña para D. Alfonso y Sicilia para D. Jaime, pero además hace firmar a D. Alfonso la expresa renuncia a todo derecho sobre Sicilia ${ }^{60}$. Era la confederación dinástica.

\section{EL ARAGONISMO DINÁSTICO DE JAIME DE SICILIA (1285-87)}

Muy al contrario el fracaso de colaboración dinástica entre Pedro III y Jaime II de Mallorca, D. Jaime conocía la extrema inseguridad de su trono siciliano y la necesaria dependencia de Aragón, por lo que se esforzó en un correcto funcionamiento de la confederación dinástica. La realidad impondría un ritmo distinto a los deseos.

\subsection{Los actos de continuismo}

Tanto D. alfonso en Aragón como D. Jaime en Sicilia habían sido fieles testaferros de la política paterna, por los que conocían perfectamente los proyectos de Pedro III y sus designios sobre la confederación dinástica. Ambos hermanos pudieron practicar en puridad un adherente continuismo político. La iniciativa claro, correspondía a Aragón.

La conquista de Mallorca se realizó en el más estricto sentido continuista. Proyectada por Pedro III, D. Alfonso decidió su inmediata realización para lo cual necesitaba el imprescindible concurso de la armada de Roger de Lauria. El almirante prestó su colaboración ${ }^{61}$ después de protagonizar un acto que reforzaba la confederación dinástica: el 25 de noviembre de 1285, ante el almirante, D. Alfonso juraba defender la corona siciliana de $D$. Jaime y acto seguido Roger de Lauria apoyar a ambos en sus

59 En agosto de 1285 Pedro III hacía pública la recepción de tres embajadores del Príncipe de Salerno. ACA, Reg. 57, f. 182. Pub. LA MANTIA, Ibídem, nº 97, pp. 195-6.

60 Cit. ambos documentos, G. CARINI, Gli Archivi.., obr. cit., pp. 204-206 y 182 respectivamente.

61 El 25 de enero Alfonso III ordenaba a los justicias y jurados de Valencia entregar 500 quintales de pez a la armada de Lauria, ACA, Reg. 63, f. 32 v, así como pagarle cierta cantidad que él adelantó para los gastos de la armada en Mallorca, ACA. Reg. 63, f. 33. Reg. ambos A. GALLOFRE, Documentos del reinado de Alfonso III de Aragón, relativos al Reino de Valencia, Valencia 1968, no 17 y 18, p. 16. 
respectivos estados ${ }^{62}$. El almirante daba así un sentido siciliano a la conquista de Mallorca.

La conquista, iniciada en noviembre, fue muy fácil y rápida, apenas un mes ${ }^{63}$. Después de someter unos brotes nobiliarios de resistencia, Alfonso III supo reincorporar administrativa y comercialmente Mallorca en los circuitos catalanes ${ }^{64}$. En enero de 1286 se sometía Ibiza.

La recuperación de Mallorca pretendió utilizarse como un medio de reforzar las rutas marítimas que uniesen más estrechamente Aragón y Sicilia: el 22 de febrero de 1286 Alfonso III ofrecía a los líderes gibelinos italianos renovar la alianza como prueba de compromiso ${ }^{65}$; el día 23, mediante el matrimonio con su tía $D^{\mathrm{a}}$ Beatriz, sellaba la alianza con el marqués de Saluzzo en favor de Jaime I de Sicilia ${ }^{66}$; en marzo establecía Alfonso III colaboración con los mercaderes placentinos ${ }^{67}$; el 30 de marzo enviaba a Jaime Barull para renovar alianza con el juez de Arborea (Cerdeña) ${ }^{68}$.

Roger de Lauria articuló finalmente la confederación dinástica. Tomada Mallorca, llegaba a Sicilia a finales de enero de 1286 y quizás coordinó una simbólica ceremonia: el mismo día, 2 de febrero, Alfonso III se coronaba rey de Valencia, mientras Jaime I lo era como rey de Sicilia en la catedral de Palermo por los obispos de Cefalú, Squilacce y Neocastro. El 12 de febrero, Jaime I juraba el mismo documento que Alfonso III el pasado 25 de noviembre.

Enseguida la confederación dinástica tomo cariz de perfecta simbiosis: Aragón aporta la fuerza militar y Sicilia compensa con un lucrativo comercio, siendo los garantes Lauria, Prócida y $D^{a}$ Constanza ${ }^{69}$. El 18 de febrero Jaime I otorga el monopolio de exportación de trigo siciliano a los catalanes, quienes el día 22 reciben nuevos privilegios y un consulado en Sicilia ${ }^{70}$. Ese 22 de febrero, Alfonso III advertía a $\mathrm{D}^{\mathrm{a}}$ Constanza que D. Jaime Pérez (bastardo de Pedro III) pasaba con tropas a Sicilia en servicio de Jaime ${ }^{71}$. Para facilitar el paso el rey ordenaba la prórroga de deudas por $D$. Jaime Pérez y sus hombres ${ }^{72}$. Ambos hermanos, pues, deciden aplicar sus fuerzas confederadas en dos campos:

62 Cit. G. CARINI, Gil Archivi..., obr. cit., p. 208.

63 Efecto de la firma voluntad regia y los sólidos intereses aunados de las burguesías barcelonesa y mallorquina. cit. A. RIERA MELIS, La Corona de Aragón y el Reino de Mallorca en el primer cuarto del siglo XVI, Barcelona, 1986, pp. 69-70.

64 Política detalladamente expuesta por A. SANTAMARÍA ARÁNDEZ, "La política municipal de Alfonso el Liberal en el Reino de Mallorca (1285-1291)", pp. 1271-1299, en La Ciudad Hispánica durante los siglos XIII al XVI, Madrid, 1985, pp. 1280-84.

65 ACA, Reg. 63, f. 69.

66 Largo y clarificador documento, ACA, Reg. 63, f. 72v.-73.

67 El monarca confirmaba a sus oficiales la especial protección a estos mercaderes de Mallorca y, a cambio, éstos conceden un empréstito de 4.000 sueldos reales, ACA, Reg. 66, f. $7 \mathrm{v}$.

68 ACA, Reg. 64, f. 26.

69 La Reina procuraba mantener su influencia en Aragón. El 11 de mayo de 1286 obtenía de Alfonso III una asignación económica para su canónigo Jimén Cuscull. ACA, Reg. 75, f. 7.

70 Pub. LA MANTIA, Códice diplomático dei..., obr. cit., $n^{\circ} 191$ y 192, pp. 306-309.

71 ACA, Reg. 63, f. 65.

72 ACA, Reg. 63, f. 90 v. 
$1^{\circ}$ Militar. Puesto que Alfonso III continuaba en guerra con Francia y sus aliados (hubo un desmayada invasión de Jaime II de Mallorca a Cataluña entre marzo y julio de 1286), Jaime I reactivó el frente marítimo siciliano. Roger de Lauria depredó el Midi francés, mientras Bernardo de Sarriá y Berenguer Villarant cercaban las costas de sur italiano del Tirreno al Adriático.

$2^{2}$ Legitimismo dinástico. Muy seguro de sus derechos, una vez coronado, Alfonso III notificaba a Honorio IV y el Colegio cardenalicio sobre el envío de una embajada para defender sus legítimos derechos ante la Santa Sede ${ }^{73}$, el 1 de marzo de 1286. Subrepticiamente enviaba cartas personales a una parte del Colegio, filoaragonesa, a la que proponía persistir en esa inclinación aragonesista ${ }^{74}$. Mucho más astuto, el 3 de abril, Alfonso III acreditaba ante el Arzobispo de Tarragona a Pons de Monpaó para argumentar desde el Derecho canónico su legitimidad regia, argumentación que expondrían al Papa un clérigo aragonés y otro catalán ${ }^{75}$, muestra inequívoca del monolítico apoyo de la Iglesia catalano-aragonesa a la casa de Barcelona. entretanto, con sendas órdenes del 25 de marzo y 27 de mayo Alfonso Ill mantenía la violencia paterna para que no se publicasen las sentencias pontificias.

En estricto paralelismo actuó Jaime I, al que preocupaba la afirmación de soberanía de Honorio IV sobre Sicilia el 2 de enero de $1286^{76}$. Nada más coronarse enviaba a Gilberto de Castellet y Bartolomeo de Neocastro para ofrecer se obediencia al Papa, entre otros gestos de sumisión ${ }^{77}$. Por toda respuesta, Honorio IV exigió volver a la situación anterior a las Vísperas.

\subsection{Los actos de distorsión}

Aún a pesar de que durante los años 1286 y 1287 Alfonso III persiste en la idea de que la confederación dinástica es beneficiosa para sus estados, tres factores ensombrecen progresivamente esta perspectiva hasta principiar los desencuentros con Jaime I.

$1^{\circ}$ La política de Honorio IV, madura y diferenciada de la de Martín IV ya en 1286. Partidario de reeditar el "dominium mundi», la posesión de Sicilia por la Santa Sede era su espacio material y un güelfismo manejable por parte de los estados angevinos (nunca la poderosa Francia) el brazo armado del Papado. Sicilia y la libertad del Príncipe de Salerno, pues eran los supuestos prioritarios de su política y ambos pasaban por Aragón. Una alambicada política pontificia buscó el entendimiento con Alfonso III para separarle de Jaime I y predisponerle sobre la conveniencia de liberar a D. Carlos de Salerno.

73 Ambos documentos, ACA, Reg. 63, f. 92 r y v.

74 Cardenales Latino, Albano, Jerónimo, Mateo, Jordano y Jacopo Colonna. Ese día 1 de marzo, solicitaba el tradicional auxilio jurídico de Raimundo de Ponte. ACA, Reg. 63, f. 94v-95.

75 ACA, Reg. 63, f. 31 v.

76 Ordena no cubrir vacantes, a disposición papal, todas la iglesias sicilianas que perdiesen su titular. Reg. M. PRON, Les Registres d'Honorius IV (1285-87), Paris, 1888, n 490, col. 347.

77 El 22 de febrero Jaime I recibía en custodia la Orden del Hospital de Santa Mª de Teutónicos de Jerusalén. Reg. LA MANTIA, Códice diplomático dei..., obr. cit., nº 143, p. 309. 
Por entonces, fiel a la confederación dinástica, Alfonso III aislaba al Príncipe de Salerno en el castillo de Ciurana y allí, desinformado, desde abril de 1286 acometía unas conversaciones tendentes a confirmar lo pactado con Jaime I en Cefali ${ }^{78}$. Honorio IV actuó enseguida. El 11 de abril de 1286 confirmaba las sanciones contra Alfonso III, Jaime I, $\mathrm{D}^{\mathrm{a}}$ Constanza y los sicilianos ${ }^{79}$, pero suspendería la aplicación en Aragón si Alfonso III satisfacía los derechos de la Santa Sede (una imposible devolución de Sicilia) o enviaba una embajada a Roma, sabiendo que el aragonés ya la preparaba. Aún más, el 5 de mayo recibía unos enviados de Eduardo I de Inglaterra a quienes confirma que aprobaría sus gestiones mediadoras en Aragón. El 2 de mayo los hijos del Príncipe de Salerno y los eclesiásticos angevinos habían aceptado también la mediación inglesa.

Otras eran las expectativas de Alfonso III respecto a la mediación inglesa: obviar al Papa y la Jaime II de Mallorca y abrir a Francia la sucesión del trono castellano a cambio de que Felipe IV olvidase la reclamación de Sicilia ${ }^{80}$. El 18 de mayo comunicaba al Príncipe de Salerno que Jaime I de Sicilia sólo se avendría a liberarle si renunciaba expresamente a Sicilia ${ }^{81}$. Honorio IV respondió con contundencia: anima a los catalano-aragoneses a la rebelión en favor de $\mathrm{D}$. Carlos de Valois y el 23 de mayo reitera la excomunión de Jaime I por su criminal coronación ${ }^{82}$, como también la de Alfonso III, si bien insiste el reservarse a proceder si era enviada a la embajada.

Alfonso III recapacitó. A través de una carta del Príncipe de Salerno al Papa el 22 de junio, el monarca aragonesa sugería reconocer el ius utile de Sicilia para Jaime I y el ius eminens para el Príncipe. Todo su entramado se vino abajo por la confluencia de tres sucesos adversos: el 24 de junio la Unión amenaza con destronar a Alfonso III (necesitará el refrendo papal); bajo presidencia de Eduardo I la legación francesa exigió la inmediata libertad del Príncipe de Salerno e incluir el asunto de Mallorca; el 21 de junio, enérgico, Jaime I le advirtió que nunca aceptaría una paz que no le reconociese la plena soberanía sobre Sicilia y que no podía garantizar la seguridad de una embajada aragonesa contra este axioma ${ }^{83}$, incluso expresó serias dudas sobre la lealtad de su hermano ${ }^{84}$. Más aún, decidido al sabotaje por entonces Jaime I notificaba al Papa que nunca abandonaría Sicilia.

78 El monarca aragonés el 4 de abril permitía al Príncipe entrevistarse con Jacomo de Bonsó y el Preboste de Marsella, sin duda para acuciarle en la necesidad imperiosa de ocupar enseguida su trono. Pub. L. D'ARIENZO, Documenti sulla prigionia.., obr. cit., no 6, p. 510, ACA, Reg. 66, f. 33 v.

79 Reg. A. POTTHAS, Regesta Pontificum..., obr. cit., no 22414, p. 1810; pub. M. PRON, Les Registres..., obr. cit., no 494, col. 348-9.

80 El 5 de mayo el rey aragonés constituía sus embajadores a Pedro Martínez de Artusona y Juan Zapata para tratar la tregua con Francia. Significativamente, el 13 de mayo les son expedidas

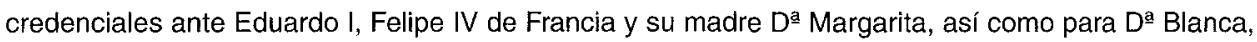
madre de los Príncipes de la Cerda, ACA, Reg. 64, f. 179 a $180 \mathrm{v}$.

81 ACA, Reg. 64, t. 181, pub. L. D’ARIENZO, Documente sulla prigionia..., obr. cit, no 13, pp. 513-4.

82 Reg. A. POTTHAS, Regesta Pontificum..., obr. cit., no 768, col. 557.

83 Pub. G. LA MANTIA, Códice diplomático dei..., obr. cit., nº 147, pp. 320-1.

84 El 21 de junio Alfonso III hubo de asegurar a Jaime I sobre la imposibilidad de que el Príncipe de Salerno se «evadiese", ACA, Reg. 64, f. 183. 
En esta encrucijada, Alfonso III apostó por conciliar las líneas opuestas. Por un lado, en julio de 1286 tomaba medidas para sostener militarmente Sicilia ${ }^{85}$, lo que supuso la recompensa de Jaime I a los intereses mercantiles catalanes ${ }^{86}$, de otro lado buscó rentabilizar la mediación inglesa y la embajada a Roma. La mediación inglesa se agostó en el "congreso" de París, donde Eduardo I sólo arrancó una tregua franco-aragonesa hasta el 29 de septiembre de 1287. Reconociendo su fracaso, Eduardo I insistía en agosto para reconducir las negociaciones ${ }^{87}$.

La embajada a Roma para demostrar la legítima entronización de Alfonso III pareció más fructífera. El 12 de julio el monarca encargaba a Ramón de Muntanyana y Bertrán de Vall obtener el pleno respaldo a su legitimidad por parte de un amplío sector de la nobleza y clero catalano-aragoneses ${ }^{88}$. No creyó el rey encontrar obstáculos en este trámite (pese al proselitismo de la Unión entre las ciudades durante agosto de 1286) y el 21 de agosto advertía a sus partidarios en Roma la próxima llegada de su embajada, noticia que transmitió oficialmente al Papa y el Colegio cardenalicio el 3 de septiembre ${ }^{89}$. Acometidos sus primeros gastos ${ }^{90}$, el 20 de septiembre constituía la legación y extendía cartas de recomendación y asistencia en Roma ${ }^{91}$.

Sicilia, otra vez, fue el escollo. En agosto y septiembre de 1286 se aliaba con Francia y hacía colectas para invadir Sicilia. En respuesta, el 2 de octubre Jaime I hacía que su tía $\mathrm{D}^{\mathrm{a}}$ Beatriz le cediese todos sus derechos a Sicilia ${ }^{92}$, confirmando su legitimidad Staufen, pero además presionó a un Alfonso III acosado por la Unión para revalidar la perfecta sintonía de intereses en octubre ${ }^{93}$. Asi pues, aunque la embajada aragonesa debió partir hacia Roma a principios de noviembre ${ }^{94}$, al tiempo que el 6 de noviembre Honorio IV acreditaba a los arzobispos de Ravenna y Monreale ante Eduardo

85 El 2 de julio ordenaba a Castellfabib y otros lugares pagar cierto tributo con destino a la expedición de Sicilia, ACA, Reg. 68, f. 81. Reg. A. GALLOFRE, Documentos del reinado..., obr. cit., no 310, p. 75 .

86 Estipulaba el pago de un terreno para construir la Lonja de catalanes. Pub. LA MANTIA, Códice diplomático dei..., obr. cit., nº 149, pp. 323-5.

87 El 1 de septiembre de 1286 Alfonso III accedía a entrevistarse con el monarca inglés. ACA, Reg. 66, f. 180.

88 ACA, Reg. 66, f. 151. El 31 de julio repetía el cometido esta vez para el reino de Valencia.

89 Primer documento, ACA, Reg. 66, f. $166 \mathrm{v}$ y el segundo ACA, Reg. 64, f. $183 \mathrm{v}$.

9070 libras tornesas para gastos corrientes y pagos a la Curia pontificia, ACA, Reg. 65, f. 166.

91 Gilabert de Cruilles, Rodrigo Sánchez de Calatayud, Pedro Costa y Ramón de Besalú. El 21 de septiembre el rey los recomendaba a la facción filoaragonesa del Colegio, y el 8 de octubre a Pandulfo Savelli, hermano del Papa. ACA, Reg. 64, f. 187, ambas.

92 Cit. G. CARINI, Gli Archivi..., obr. cit, pp. 209-210.

93 El día 19 el aragonés ordenaba liberar a dos protegidos de Ramón Monterol, notario de Jaime I, ACA, Reg. 64, f. 129 v. Poco después, Alfonso III sugirió entregar a Alamino de Lentíni, conspirador contra Jaime I.

94 El 13 de noviembre se pagó al conde de Urgell el valor de unas bestias perdidas «in uiatico quod fecerunt apud collem panicars in nostro seruitio", ACA, Reg. 65, f. 163. 
I para tratar con los aragonese ${ }^{95}$, lo cierto es que Alfonso III no tenía voluntad de entretenimiento: el 4 de noviembre tomaba disposiciones para una larga prisión del Príncipe de Salerno. Sicilia era una rémora diplomática.

$2^{\circ}$ Las Baleares. Ocupada Mallorca para apuntalar la ruta a Sicilia, por imperativo geográfico fomentó una orientación al Magreb y Estrecho de Gibraltar ${ }^{96}$, que insensiblemente afectó a la política mediterránea de Alfonso III.

Respecto a Túnez, denunciado el tratado de Panicars por Abu Hafs al morir Pedro III, Alfonso III pergeñó tres rasgos innovadores: la penetración territorial (Roger de Lauria conquistó islas litorales); desplazar a genoveses y pisanos; imponer su primacía a Jaime I por tener Sicilia derechos feudales sobre Túnez ${ }^{97}$. En la primavera de 1286, entretanto, Alfonso III protagonizó una ofensiva diplomática en Marruecos, Granada y Tremecén ${ }^{98}$, con desigual suerte: Tremecén aceptó un auténtico vasallaje; Granada (instigada por Génova) derivó a un conflicto con Aragón en diciembre; mientras, pese a una reiterada insistencia ${ }^{99}$ Marruecos declinaba una colaboración en diciembre.

Estas tendencias esbozadas esa primavera habrian de acentuarse cuando en enero de 1287 Alfonso III conquistó Menorca, con expresa y significativa participación de la armada siciliana ${ }^{100}$. En la perspectiva de Alfonso III las Baleares son el fundamento y Sicilia sólo el coadyuvante en el Mediterráneo.

La posesión de Baleares, empero, tuvo un serio inconveniente: eran base imprescindible para la expansión genovesa hacia Magreb y Flandes. en verano de 1286 la actividad corsaria genovesa contra mercaderes catalanes era intensa y de nada sirvieron los gestos apaciguadores de Alfonso III $^{101}$.

3ํㅡㄹ al autonomismo siciliano. A pesar de la influyente posición coagulante de $D^{a}$ Constanza entre sus hijos ${ }^{102}$, la consolidación del régimen sículo-catalán, la vivificante

95 El 7 de noviembre el Papa ordenaba a sus plenipotenciarios negociar con los aragoneses con flexibilidad e informándole constantemente. Reg. A. POTTHAST, Regesta Pontificum..., obr. cit. nº 22527, p. 1818.

96 Cit. F. SEVILLANO COLOM, Historia del Puerto de Palma de Mallorca, Palma, 1974, destaca el círculo de vientos y corrientes marítimas Mallorca-lbiza-Valencia-Málaga-Melilla-Túnez-Mallorca, p. 153.

97 Cit. el objetivo Ch. E. DUFOURCQ, L'Espagne catalane..., obr. cit., p. 280.

98 En marzo y abril envió como embajadores a Pere de Deu en Marruecos, ACA, Reg. 64, f 26 , a Ramón de Sant Liceri en Granada, ACA, Reg. 64, f. 177, a Pedro García en Tremecén, ACA, Reg. 66 , f. 61, a quien el 1 de mayo el rey aplazó deudas por la legación en Tremecén.

99 Nada obtuvo Pere de Deu y en mayo Alfonso III insistía con Abraham y Samuel Abengalell, sin resultados porque el califa Abu Ya'qub ofrecía un protectorado sobre la presencia catalana en la zona. Aún así el 15 de diciembre daba credenciales a Pere de Deu, los Abengalell y Vidal Porta ante Abu Ya'qub, ACA, Reg. 72, f. 48 v. El 21 de diciembre ordenó a Berenguer Mathoses y Francisco Burquet su traslado. La nueva legación ofrecía seguridad mutua de súbditos y mercancías, alianza y colaboración militar (naves aragonesas por zenefes marroquíes) ACA, Reg. 64, f. 176 r y v. Inútil por la alianza aragonesa con Tremecén, el conflicto con Granada y la conquista de Menorca.

100 Orden a Roger de Lauria, ACA, Reg. 64, f. 184.

101 El 8 de octubre el monarca aragonés advertía a Génova que la embajada destinada a Roma, se detendría en la ciudad Ligur, ACA, Reg. 64 , f. 187, sin duda para despejar recelos.

102 El 18 de junio de 1287 Alfonso III entregó rentas y derechos en Tornos a su hermano el infante D. Pedro por orden de Da Constanza, ACA, Reg. 70, f. 171. 
energía económica del trigo siciliano en Aragón ${ }^{103}$ y los servicios de Sicilia en la integración aragonesa en los grandes circuitos económicos y diplomáticos ${ }^{104}$, convencieron a Jaime I que la confederación dinástica debía ser sinalagmática, proporcionada a su función en Sicilia. El traslado el 18 y 19 de febrero de 1287 por Giovanni Prócida de los documentos del 25 de noviembre de 1285 (cesión de todos sus derechos a Sicilia por Alfonso III y la mutua asistencia entre Jaime I y Alfonso III, demostraban un claro sentido reivindicativo.

Jaime I optó por plantear su afirmación sicilianista en dos delicados asuntos: Túnez y el Príncipe de Salerno. Al parecer, Jaime I reclamó a Alfonso III para Sicilia la soberanía feudal sobre Túnez, en tanto que le hacía saber que sólo admitía la libertad del Príncipe según las condiciones de Cefalú y Ciurana. El 27 de febrero de 1287 nombraba sus procuradores ante Alfonso III a Gilberto de Castellet y Bertrán de Canellas, a quienes el 3 de marzo da plenos poderes para tratar con el Príncipe y los regentes angevinos, mientras el 8 de marzo les faculta para tratar sobre Sicilia y Túnez ${ }^{105}$. De nuevo Alfonso III optó por el entendimiento. En marzo, el monarca aragonés enviaba a Sicilia a Conrado Lanza ${ }^{106}$ para negociar compartir el tributo tunecino e imponerlo a Abu Hafs. Jaime I debió aceptar pero el califa tunecino negó rotundamente tributo y vasallaje, por cuanto el 9 de junio suscribía un acuerdo comercial con Génova. De nada sirvió que Alfonso III el 30 de julio de 1287 coronase en Jaca califa tunecino a Abu Malik Abdalwahid, quien aceptaba tributo y vasallaje compartido entre Aragón y Sicilia ${ }^{107}$ : en conminaba sin convicción a Abu Hafs, a través del nuevo cónsul del ponduk catalán Berenguer de Segalars asumir el tributo.

En la cuestión del Príncipe de Salerno, la auténtica batalla diplomática, la confederación dinástica no fue tan resistente. En respuesta a requerimientos de Eduardo I en diciembre de $1286^{108}$, en enero de 1287 Alfonso III destacó a Burdeos a Pedro Martínez de Artasona y en febrero retomaba el diálogo con Roma ${ }^{109}$. A instancias de Pedro Martínez, Alfonso III rehusó enviar una embajada ante Eduardo I ${ }^{110}$, hasta conocer las

103 El 8 de enero de 1287 Alfonso III pagaba una deuda a Bonanato di Rippa sobre rentas reales en las partidas de trigo siciliano, ACA, Reg. 64 , f. 48 v.

104 El 12 de marzo mercaderes catalanes suscribían sociedad con florentinos, ACA, Reg. 64, f. 162 v. El 30 de marzo el sultán de Babilonia concedía especial protección a los mercaderes catalanes, por lo que Alfonso III le envió a Bertrán de Caldas para sellar alianza, ACA, Reg. 64, f. 175; el monarca concedía permisos exportadores a mercaderes catalanes hacia Mallorca, Sicilia y Túnez el 27 de marzo, ACA, Reg. 70, f. 182.

105 Cit. G. CARINI, Gil Archivi..., obr. cit, p. 212.

106 El 28 de febrero Alfonso III ordenó pagar a Conrado Lanza 4.000 sueldos barceloneses para gastos de su embajada en Sicilia y Túnez. ACA, Reg. 72, f. 48 v.

107 Pub. G. LA MANTIA, Códice diplomático dei..., obr. cit, no 168, pp. 377-383.

108 El 18 de diciembre el rey aragonés ordenaba sufragar los gastos de unos embajadores ingleses, ACA, Reg. 72, f. 12 v.

109 El 5 de febrero el monarca aragonés aprestó a Peironeto Crocerio como su enviado ante el Papa, ACA, Reg. 72, f. 52.

110 La carta de Pedro Martínez en ACA, Reg. 64, f. 192 v. El 6 de marzo, en efecto, Alfonso III disculpaba un retraso en la embajada, ACA, Reg. 64, f. 193. 
intenciones pontificias a través de los plenipotenciarios arzobispos de Ravenna y Monreale, que llegaron a Burdeos a fines de Febrero. En efecto, Honorio IV no tardó en hacer diáfanas sus intenciones: el 4 de marzo arrebataba toda iniciativa a la mediación inglesa, y declaraba nulos, por irracionales, los acuerdos de Cefalú-Ciurana para liberar al Príncipe de Salerno. El 20 de marzo, entonces, Alfonso III constituía su embajada, a la que el 21 dio plenos poderes e instrucciones de negociación en Burdeos con los legados pontificios ${ }^{111}$ : junto a la razón aragonesa de ocupar Mallorca y Albarracín, reclamar indemnizaciones por la invasión de 1285 y proteger a los Príncipes de la Cerda contra Sancho IV de Castilla, Alfonso III insistía en hacer reconocer su legitimidad regia por los testamentos de Jaime I y Pedro III, así como hacer aceptar a Jaime I como rey "tenente» de Sicilia (ius útile), quien satisfaría todos los derechos de la Iglesia (soberanía y ius eminens para la Santa Sede).

Era una vía muy poco grata para Jaime I, sobre todo porque desde comienzo de 1287 Honorio IV hacía intensos preparativos bélicos para invadir Sicilia por Agosta, Lentini y Catania. A pesar de la muerte del Papa el 3 de abril, una armada papal y angevina ocupó Agosta el 1 de mayo. Jaime I comprobó entonces la solidez de su régimen: Sicilia se mantuvo fiel y aprestó inmediatamente un ejército y una flota. La invasión angio-pontificia quedó abortada.

Alfonso III comprendió que sin Sicilia la Santa Sede ya no tendría interés en reconocer su legitimidad regia. En junio movilizó sus fuerzas en favor de Sicilia ${ }^{112}$, mientras el 23 de junio Jaime I recuperó Agosta y Roger de Lauria aplastó la armada angevina en Castellamare. Jaime I recibió la confirmación de que Sicilia no debía supeditarse a los exclusivos intereses aragoneses: desautorizó una tregua por dos años pactada por Roger de Lauria con los regentes angevinos (el almirante se apresuró a informar a Alfonso III) y sólo admitió oportuno el desmantelamiento de los estados angevinos. Era un formidable desafío a la diplomacia de Alfonso III.

$4^{\circ}$ Olorón. Desde mediados de 1287 Alfonso III comprende que Jaime I ve su única salvación como rey siciliano aniquilando los estados angevinos, objetivo impensable para la Santa Sede. El monarca aragonés necesita al Papa para detener una Unión que ya sin ambages busca derrocarlo y también precisa clausurar las Vísperas Sicilianas para reordenar su política mediterránea. Frente a Jaime I, Alfonso III decide dar viabilidad a los estados angevinos. El 20 de junio solicitaba al Colegio cardenalicio (luego también personalmente a los cardenales filoaragoneses) su benevolencia para acabar la guerra ${ }^{113}$. Paralizada la Santa Sede por muerte de Honorio IV, el Colegio pareció delegar en Eduardo I.

En efecto, desde el 25 de julio Alfonso III y Eduardo I se entrevistaron en Olorón, junto a los plenipotenciarios pontificios (Ravenna y Monreale) y los sicilianos (Castellet

111 ACA, Reg. 64, f. $194 \mathrm{v}-195$.

112 El 2 de junio acudía a Sicilia para coordinar la estrategia sículo-aragonesa Jaime de Sant Climent, ACA, Reg. 71, f. 55 v; el 17 de junio ordenaba a sus capitanes y a los almirantes Marquet y Mallol colaborar con el enviado siciliano Berenguer de Monteolivo para armar una flota hacia Sicilia, ACA, Reg. 71, f. 60 v; El 29 de junio fomentaba la piratería contra Provenza, ACA, Reg. 70, f. 154.

113 ACA, Reg. 64, f. 196 v. 
y Canellas) ${ }^{114}$. En Olorón se establecieron las condiciones para liberar al Príncipe de Salerno, la alianza anglo-aragonesa y la potestad a Eduardo I para ampliar la tregua franco-aragonesa que expiraba el 29 de septiembre.

Nada más irritante para Jaime I. El 27 de julio un cauto Alfonso III notificaba a su hermano la próxima liberación del Príncipe, noticia transmitida también a Giovanni Prócida y Roger de Lauria para aplacar la cólera de Jaime 1115. Alfonso III, el 4 de agosto, hizo tres gestos comprometedores para evitar el sabotaje de Jaime I: le entregaba, con permiso de asesinato, a Alaino de Lentini (símbolo de la resistencia al régimen de Jaime I); confirmaba a las ciudades sicilianas que todos los pactos se hacían en pro de Sicilia y reiteraba la denuncia a sus derechos sicilianos como la colaboración naval sículo-aragonesa ${ }^{116}$. El 25 de septiembre advertía que sólo ratificaría una tregua que Jaime I considerase oportuna ${ }^{117}$.

Olorón fracasó por el boicot de la Unión y la oposición de Jaime I de Sicilia, Jaime II de Mallorca, Felipe IV de Francia y el Colegio Cardenalicio, pero se abrió un canal de solución para la Vísperas y una vía de desencuentro con Jaime de Sicilia.

\section{LA ITALIANIZACIÓN POLÍTICA DE JAIME I (1288-1291)}

\subsection{Los nuevos factores}

Olorón, además, desató otro factor determinante: la participación de Francia. Felipe IV había contemplado sin simpatía la ocupación aragonesa de Mallorca, pero cuando el Olorón Alfonso III reclamó vasallajes en Provenza temió un renacimiento occitánico. La directa intervención pareció el antídoto adecuado. El 9 de diciembre de 1287 Felipe IV ordenaba al Senescal de Carcasona secundar los proyectos aragoneses de Jaime Il de Mallorca, por lo que el 26 de diciembre el monarca advertía al mismo Senescal y al Gobernador de Navarra que ya no existía tregua con Aragón ${ }^{118}$. En enero y febrero de 1288 tropas de Jaime II, Carlos de Valois y los plenipotenciarios pontificios se reunían en Rosellón, mientras Felipe IV promovía preparativos navales en Languedoc. Alfonso III temió la edición de una nueva Cruzada y entre enero y abril de 1288 dispuso defensas navales, levas y refuerzo de castillos.

Peor aún, por entonces llegaban ante Alfonso III Guillem Durfort y Conrado Lanza con la noticia de que Jaime I rechazaba la tregua de Roger de Lauría con los regentes angevinos e insistía en que la única solución era el desmantelamiento del poder angevino. Alfonso III desvió esta legación a Eduardo I como prueba de que urgía com-

114 Alfonso III cuidó la presencia siciliana. El 27 de junio ordenó a Jaime Pérez responder de 25.000 sueldos que Roger de Lauria recibió de Jaime I para el ornato y caballos de su embajadores que irían a Olorón. ACA, Reg. 70, f. 146.

115 ACA, Reg. 71, f. 170

116 Los dos últimos documentos en ACA, Reg. 70, f. 162 v y Reg. 74, f. 30.

117 ACA, Reg. 64, f. 197.

118 Cit. L. KLÜPFEL, «Die Aüssere politik von Alfons IIl», Aragonensia, pp. 1-174, Leipzig, 191112 , en p. 43. 
prometer a Francia con la tregua ${ }^{119}$. Para evitar sabotajes franceses, el 20 de febrero ambos monarcas pactaron un encuentro secreto de representantes en Perpiñán ${ }^{120}$. Eduardo I evitó el menor compromiso, porque el 22 de febrero era electo nuevo Papa Nicolás IV. El nuevo pontífice no tardó en manifestar la plena continuidad con la política de Honorio IV: en marzo primero descalificó y luego sepultó con sentencias pontificias Olorón ${ }^{121}$; el 13 de marzo a los arzobispos de Rávenna y Monreale unía Rayno de Virterbo para negociar la liberación del Príncipe de Salerno; el 15 de marzo exhortaba a Alfonso III abandonar a Jaime I'22, a quien el 25 de exigía la incondicional devolución de Sicilia.

Sin consultar a Jaime I, Alfonso III, convencido de su superioridad agnaticia dinástica, ensayó una contraofensiva en mayo de 1288: nuevos alegatos sobre su legitimidad ante el nuevo Papa ${ }^{123}$, concertar vistas con Eduardo $\mathrm{I}^{124}$ y firmar una tregua el 24 de mayo con $D^{a}$ María, esposa del Príncipe de Salerno, idéntica a la establecida por Roger de Lauria ${ }^{125}$.

Sin embargo a nadie interesaba la vía diplomática. Nicolás IV encargaba el 1 de mayo a Eduardo I obtener la liberación del Príncipe de Salerno, pero ese día suscribía empréstitos para recuperar militarmente Sicilia y el día 6 reiteraba durísimas condenas contra Jaime ${ }^{126}$. Aún más, el Papa se empeñó en enturbiar una fórmula de entendimiento entre Génova y Aragón en el Estrecho de Gibraltar ${ }^{127}$, amparando a la República el 18 de mayo sí retiraba cualquier apoyo a Jaime ${ }^{128}$. Mientras, el 3 de mayo, en Nimes Felipe IV y Jaime II de Mallorca sellaban una alianza, por la que tropas rosellonesas invadieron el Ampurdán y tropas francesas Aragón desde Navarra.

De otro lado, Jaime I había consolidado una autonomía que le permitía corregir

119 Cit. J. ZURITA, Anales, obr. cit., pp. 333-334.

120 Carta de compromiso en ACA, Reg. 74 y f. 85. Entre abril y mayo se entrevistaron un procurador inglés y Pedro Martínez de Artasona, a quien Alfonso III ordenó pagar 4.000 sueldos turonenses de plata por su legación ante el monarca inglés, ACA, Reg. 79, f. $20 \mathrm{v}$.

121 En sendas bulas de 15 y 29 de marzo. Reg. E. LANGLOIS, Les Registres de Nicolás N (12881292), París, 1886-1893, nº 562 y 566, pp. 113-114.

122 Reg. A. POTTHAST, Regesta Pontificum..., obr. cit., p. 1827.

123 El 24 de mayo el rey ordenaba colectas en el obispado de Lérida para sostener al maestro jurista Ramón de Ponte, al servicio real en Roma, ACA, Reg. 79, f. 53.

124 El 8 de mayo Alfonso III ordenó entregar una generosa suma a un escudero inglés, $A C A$, Reg. $79, f .42 \mathrm{~V}$, sin duda presente en Aragón para organizas las vistas.

125 Cit. L. KLÜPFEL, Die Aüssere politik..., obr. cit., p. 46; J. ZURITA, Anales, obr. cit., p. 343; G. CARINI, Gli Archivi..., obr. cit., p. 223; pub. G. LA MANTIA, Códice diplomático dei.., obr. cit., nº 179, pp. 410-417.

126 Pub. E. LANGLOIS, Les Registres de..., obr. cit., no 597, p. 118.

127 El 20 de septiembre de 1287, muestra de que Génova secundaba el proyecto aragonés de una paz en Granada, para la que en julio de 1287 envió a Adán Abenhacep, ACA, Reg. 71, f. 55 , Alfonso III ordenó delegar en un mercader mallorquín y el genovés Vivaldi firmar una tregua hasta marzo de 1288, ACA, Reg. 64, f. 198 y en agradecimiento protegió la actividad naval genovesa en sus estados, permitiendo la exportación de pez, ACA, Reg. 74, f. 105 v el 28 de marzo de 1288.

128 Reg. A. POTTHAST, Regesta Pontificum..., obr. cit., $n^{\circ} 22715$, p. 1834; pub. E. LANGLOIS, Les Registres de..., obr. cit., nำ 76, p. 14. 
sus proyectos fraternos, expresando su frontal oposición a la tregua pactada con Da María el 24 de mayo. Sobresaltado, Alfonso III conminó con dureza a su hermano aceptar la tregua ${ }^{129}$ y para presentarle hechos consumados precipitó para el 1 de agosto, en Santa Cristina, vistas con Eduardo I para decidir la liberación del Príncipe de Salerno ${ }^{130}$, informándolo así enseguida al Papa mediantes dos franciscanos ${ }^{131}$, y favoreciendo una presencia de los arzobispos de Ravenna y Monreale, con Rayno de Viterbo en las negociaciones ${ }^{132}$. Jaime I supo maniobrar. No sólo recordó a los catalanes el valor de Sicilia ${ }^{133}$, sino que, obedeciendo formalmente las admoniciones pacifistas de Alfonso III, envió el 12 de junio una embajada a Roma ${ }^{134}$ con proposiciones tan opuestas a la Santa Sede (conservar el trono frente a la devolución incondicional) que cegó toda vía de entendimiento. Nicolás IV desautorizó toda negociación en torno al Príncipe de Salerno. Eduardo I hubo de suspender los preparativos de las vistas de Santa Cristina, mientras la embajada franciscana aragonesa cosechó en Roma un rotundo fracaso en julio de 1288. Mientras en agosto y septiembre el Papa reactivaba donaciones para atacar Aragón y Sicilia, el 13 de julio, en Lyon se rubricaba una solemne alianza antiaragonesa entre Francia y Castilla.

En esta coyuntura Alfonso III tomó dos medidas extremas: el 20 de agosto notificaba a Jaime I que liberaría al Príncipe de Salerno ${ }^{135}$ y el 28 de agosto permitía en Jaca la coronación de D. Alfonso de la Cerda como rey de Castilla. La ruptura con Castilla implicó un indeseado deterioro de las relaciones con Marruecos (amistado con Castilla), por lo que Alfonso III buscó un contrapeso fomentando las relaciones con Granada a través de los consulados catalanes en Almería y Málaga ${ }^{136}$, con escaso éxito.

Sin embargo, la directa intervención de Francia inquietó sobremanera a Eduardo I que veía cómo sus posesiones de Gascuña se situaban en peligrosa línea de expansión francesa. No podía permitirse fallar y activó su mediación. El 15 de septiembre el monarca inglés hace pública y enérgica protesta por el obstruccionismo de Jaime $\mathrm{I}^{137}$, mientras obligaba el compromiso de Alfonso III en la liberación del Príncipe de Salerno el 26 de Septiembre y al Príncipe a aceptar, el 4 de octubre, las condiciones de libe-

129 ACA, Reg. 73, f. 2. Pub. LA MANTIA, Códice diplomático dei..., obr. cit., nº 181, pp. 421-423.

130 En junio Alfonso III acreditó a Gilabert de Cruilles y Ramón de Besahí, concediéndoles ciertas sumas el 17 por gastos de legación ante Eduardo I, ACA, Reg. 79, f. 59 v. cit. las maniobras de Santa Cristina, L. KLUPFEL, Die Aüssere politik.., obr, cit., p. 47.

131 Para ellos solicita la asistencia en Roma de Ramón de Ponte y la facción filoaragonesa del Colegio cardenalicio, ACA, Reg. 77, f. 1.

132 Concesión de salvoconducto a los tres, el 17 de junio, ACA, Reg. 77, f. 3 v y 4.

133 Equiparaba el 17 de julio los privilegios de los catalanes a los genoveses. Pub. LA MANTIA, Códice diplomático dei..., obr. cit., $\mathrm{n}^{\circ}$ 182, pp. 424-426.

134 Reg. A. POTTHAST, Regesta Pontificum..., obr. cit., $n^{\circ} 22742$, p. 1836.

135 Expresamente declinaba el ofrecimiento naval de Jaime I, innecesario por esta medida pacificadora, ACA, Reg. 77 , f. 6.

136 Así lo expresó desde el 2 de febrero de 1288 a Guillermo López, ACA, Reg. 74, f. 65.

137 T. RYMER, Foedera, conventiones, literae et cuinscunque generis acta publica inter Reges Angliae et alios quosvis imperatores, reges, pontifices, principes vel comunitales, II, Londres, 1727, pp. 366-7. 
ración que pactasen él y el rey de Aragón. En un gesto teatral, Alfonso III confirmaba estas decisiones a las ciudades sicilianas, obviando a Jaime I y al Papa a través de sus plenipotenciarios y de una embajada directa para la que el monarca aragonés solicita especial protección ${ }^{138}$, que el pontífice concedió el 25 de noviembre una vez que el Príncipe de Salerno fue liberado tras el tratado de Canfranc el 28 de octubre. Así las cosas el 29 de diciembre Alfonso III encargó a Ramón de Riera, a quien acredita el 3 de enero de 1289, preparar la embajada ante el Papa y los regentes angevinos ${ }^{139}$. Sólo entonces, el 25 de enero de 1289 Alfonso III notificó oficialmente a Jaime I la liberación del Príncipe de Salerno ${ }^{140}$.

\subsection{El proyecto de Alfonso III}

Liberado el Príncipe de Salerno la política exterior aragonesa ya no podía ser igual. Sin embargo el rey de Aragón no tardó en comprender el error de intentar clausurar las Vísperas Sicilianas sin la supervisión francesa.

En efecto, en enero de 1289 no sólo Felipe IV apresó sin contemplaciones a los embajadores aragoneses que le informaron de la liberación del Príncipe, sino que le exhortó a coronarse rey de Sicilia ${ }^{141}$. De nada sirvió que Alfonso III advirtiese al noble castellano D. Juan Núñez de Lara (influyente en Francia por su firme apoyo a los príncipes de la Cerda), que el 7 de diciembre de 1288 había reconocido a D. Alfonso de la Cerda (primo de Felipe IV), rey de Castilla ${ }^{142}$, porque cuando entre enero y febrero dispuso la solemne embajada a Roma y ante los regentes angevinos ${ }^{143}$, los embajadores fueron presos en Narbona por instigación francesa. Presionado, el 7 de abril de 1289 Nicolás IV renovó el proceso contra Alfonso III y Jaime I, sin reconocerles el título real ${ }^{144}$. Las dolidas protestas de Alfonso III al Papa ${ }^{145}$, sólo sirvieron para que el 17 de junio el pontífice solicitase la liberación de los embajadores aragoneses a Felipe IV y sólo renovase el proceso a Jaime I.

En perfecta sintonía con la estrategia francesa, mientras Felipe IV apretaba a Aragón, Nicolás IV se lanzaba a la recuperación de Sicilia: el 29 de mayo en Rieti, coronaba al Príncipe de Salerno como Carlos II de Sicilia, vasallo de la Iglesia. Acto seguido estos aliados iniciaban la ofensiva. Mientras, en julio, tropas mallorquinas de

138 ACA, Reg. $77, \mathrm{f} 9$.

139 Sendas cartas en ACA, Reg. 79, f. 74 v y ACA, Reg. 77, f. 11 v a 13.

140 ACA, Reg. 78, f. 29.

141 Era contrario a lo pactado en Canfranc. D. Carlos de Salerno, escrupuloso, solicitó la opinjón de Alfonso III, quien se opuso enérgicamente el 26 de enero, ACA, Reg. 77, f. 15.

142 ACA, Reg. 77, f. $17 \vee$ y 18.

143 El 23 de enero eligió a Gilabert de Cruilles y Bernat Guillen de Pinels como embajadores en Roma y a Galcerán de Tímor y Pedro Costa en Sicilia, ACA, Reg. 77, f. 15 r y v; enseguida les concedió plenos poderes, ACA, Reg. 77, f. 16; el 18 de febrero les anejó al jurisperito Pedro de Solsimira, ACA, Reg. 77, f. 20 r y v, además les exhortaba a asecrarse con expertos en Barcelona, Roma y Sicilia, ACA, Reg. 77 , f. $17 \mathrm{v}$.

144 Pub. E. LANGLOIS, Les Registres de..., obr. cit., nº 2170 y 2171 , pp. 383-4.

145 ACA, Reg. 77, f. 22 a 23. 
Jaime II invadian Cataluña y las francesas Cerdaña y Aragón, Carlos II y Nicolás IV adoptaban medidas demagógicas de captación para los sicilianos y rompían hostilidades, que provocaron una contraofensiva de Jaime I hasta sitiar Gaeta el 30 de junio.

Poco antes Jaime I recibía la legación aragonesa que Alfonso Ill envió al tiempo que la apresaba en Narbona. Todo indica que, siguiendo las astutas sugerencias de Eduardo I, ambos hermanos coordinaron una inteligente acción contra el belicismo papal. Eł 14 de junio Jaime I daba plenos poderes a Gisbert de Castellet y Bertrán de Canellas ${ }^{146}$.

El plan urdido surtió efecto. En plena ofensiva pontificia, el embajador inglés Eudes Grandson recordó al Papa la calamitosa situación de Tierra Santa y la necesaria paz entre cristianos, en tanto que, so pretexto de una solicitud de Alfonso III para socorrer al reino cruzado de Chipre ${ }^{147}$, Jaime I se ofreció para una Cruzada. Impactado, Nicolás IV recomendó a Carlos II, el 18 de agosto, una tregua que el angevino suscribió con Jaime I hasta el 1 de noviembre de 1291 a finales de mes. Era un éxito no sólo porque se detuvo la peligrosa ofensiva, sino porque Nicolás IV se mostró más benévolo hacia Sicilia: el 13 de septiembre de 1289 permitía el comercio con Venecia e inició una relación epistolar continuada con $D^{\mathbf{a}}$ Constanza de Sicilia ${ }^{148}$.

Desde entonces es claro que Nicolás IV está preparando los preliminares de una paz que clausuraría las Vísperas Sicilianas, por los que debía partir de condiciones de negociación muy duras, juego que siguió admirablemente Alfonso III.

El 12 de septiembre de 1289, el Papa recordaba a Carlos II que estaba dispensando de cumplir el tratado de Canfranc, por lo que en octubre el angevino escribía a Alfonso III sobre la imposibilidad de obtener una tregua entre Aragón, Francia y el Papado, por lo que retornaría a prisión según lo pactado en Canfranc, protagonizando el único simulacro de su entrega el 31 de octubre, mientras el 18 de noviembre Nicolás IV incoaba proceso contra los obispos aragoneses, sicilianos y gibelinos italianos. Por entonces, una embajada de Carlos II, que Alfonso III se negó a recibir en persona, proponía la paz si el rey de Aragón renunciaba a Mallorca, Jaime I a Sicilia, Aragón era infeudado a la Santa Sede y la diplomacia aragonesa se subordinaba a Francia ${ }^{149}$.

Alfonso III respondió magistralmente. Demostró la excelente salud de la confederación dinástica sículo-aragonesa ${ }^{150}$, solicitando a Jaime I y sus colaboradores, el 9 de diciembre de 1289 víveres y 40 galeras para detener a los enemigos «vuestros y nuestros». Aún más, demostró al Papa que podía boicotear su ansiada Cruzada: Bizancio otorgó privilegios comerciales a los catalanes; propició acuerdos con Egipto ${ }^{151}$ que

146 Cit. G. CARINI, Gli Archivi..., obr. cit., pp. 232-233.

147 ACA, Reg. 77, f. 24 v a 25.

148 Sólo como muestra, el 20 de junio de 1290 el Papa solicitó a la reina que favoreciese en la exportación de trigo a Roma a Juan Macario, mariscal pontificio enviado a Sicilia. Reg. F.J. MIGUEL, Regesta de las letras..., obr. cit., $\mathrm{n}^{\circ} 205$, pp. 115-6.

149 Cit. J. ZURITA, Anales, obr. cit., p. 397.

150 El 10 de octubre solicitó a Jaime I un rehén para canjear por Gilabert de Cruilles, ACA, Reg. 80 , f. $65 \mathrm{v}$.

151 En octubre de 1289 ciertos egipcios visitaban la corte aragonesa, pues el rey ordenaba al baile de Cataluña conocer el «Fuego griego" y construir tres o cuatro lanzaderas para proyectarlo. ACA, Reg. 80, f. 67. 
culminaron con la instalación de un fonduk catalán en Alejandría para abril de 1290; el 27 de enero ofrecía una amplia colaboración a Génova ${ }^{152}$; el 4 de enero de 1290 proponía a Granada alianza política y protección mercantil oficialmente, aunque oficiosamente sugería el rey nazarí combatir a Castilla, igualar los privilegios de catalanes a los genoveses y obtener beneficios en las aduanas y el concurso de los zenetes ${ }^{153}$.

Los gestos no podían ocultar los hechos. Comisionados franceses, aragoneses y de Jaime II de Mallorca se reunieron en enero de 1290, en Perpiñán, para evaluar los daños de la invasión de 1289 y el 3 de febrero llegaban a un acuerdo ${ }^{154}$. De otro lado, para ver los efectos de la ofensiva diplomática y en calculada maniobra, Alfonso III preparaba en febrero de 1290 una nueva embajada a la Santa Sede ${ }^{155}$, coincidiendo con la llegada a Roma de Giovanni Prócida para impetrar la absolución del entredicho pontificio para Sicilia ${ }^{156}$.

Nicolás IV vio llegado el momento de actuar. Evasivamente encargó estudiar los asuntos sicilianos a los cardenales de San Nicolás y Santa Sabina, pero respecto a Aragón advirtió que previo a una negociación era el acuerdo de Alfonso III y Carlos II, esto es, una solución siciliana.

Obedeciendo al Papa, Carlos III tomó la iniciativa de unas vistas que enseguida aceptó Alfonso III el 15 de marzo ${ }^{157}$ para el 23 de abril entre Panigars y la Junquera ${ }^{158}$. en ellas, Alfonso III aceptó una conferencia multilateral para acabar con las Vísperas y se comprometió a lograr la anuencią de Jaime I.

\subsection{La clausura de las Vísperas Sicilianas}

Desde la primavera de 1290, Acre, último bastión cruzado vive un asedio agónico, obsesionando a Nicolás IV. La Cristiandad, además, teme el cierre del Mediterráneo oriental. El contencioso de las Vísperas era un estorbo para diseñar un necesario «nuevo orden».

Acabadas las vistas con Alfonso III, Carlos II acude a París y arranca dos acuerdos decisivos; el 18 de mayo Carlos de Valois, por matrimonio con $D^{a}$ Margarita (hija

152 Credenciales al doctor en leyes Galvany y al caballero Arenys con memorial para exponer en Génova la "liberación" de Sicilia por Pedro III, ofrecer la continuidad de los privilegios genoveses en Mallorca y Sicilia, la mutua neutralidad en conflicto y protección contra la piratería, ACA, Reg. 73 , f. 72 v a 73 v.

153 Credenciales y memoriales público y secreto a Abraham Abenamies en ACA, Reg. 73, f. 70 a 71 .

154 ACA, Reg. 81, f. 8 v y Reg. 73, f. 72 v.

155 Entre los días 7 y 10 de febrero el monarca solicitó la colaboración de nobles romanos y de los cardenales filoaragoneses, el consejo de los eclesiásticos catalano-aragoneses y enunció su misión: legitimidad de su título. ACA, Reg. 73, f. 75 a $77 \mathrm{v}$.

156 Cit. J. ZURITA, Anales, obr. cit, p. 402

157 Para prepararlas envió ante el angevino a Berenguer Puiguert y fray Ramón de Ripoll, ACA, Reg. 82, f. 24 v. Preparativos y seguros a los emisarios angevinos se encuentran el 24 de marzo en ACA, Reg. 81, f. 73 v, 77 v-78 y Reg. 73, f. 79.

158 ACA, Reg. 81, f. 79 v y 80. 
de Carlos II), obtenía los ducados de Anjou y Maine a cambio de renunciar a sus derechos sobre Aragón; al día siguiente, Felipe IV aceptaba esta renuncia y una paz con Aragón, si era deseo del Papa. En junio de 1290, los nuevos plenipotenciarios pontificios, cardenales San Nicolás y Santa Sabina, llegaban a Montpellier e inmediatamente contactaban con Alfonso $11{ }^{159}$, quien el 7 de junio destacaba a Ramón Cabrera ante la Santa Sede en defensa de sus argumentos legitimistas ${ }^{160}$.

Alfonso III, entonces, comenzó a preparar la espinosa cuestión siciliana. El 17 de mayo, una carta suya a Mesina sugiere que aceptaba una retirada efectiva de Sicilia ${ }^{161}$, por lo que el 19 de mayo enviaba a Bernardo de Bellvis para explicar a Jaime I lo tratado en las vistas con Carlos II ${ }^{162}$. Tortuosos debían ser los proyectos de Alfonso III sobre Sicilia, porque Jaime I, el 14 de junio, confirmó los plenos poderes en la negociación a Gisbert de Castellet y Bertrán de Canellas, pero además aceptaba casar a su hermana $D^{a}$ Violante con un alto dignatario en Roma para influir sobre el Papa, siguiendo el consejo de Alfonso III $^{163}$. Aún más, los plenipotenciarios sicilianos coordinaron estrategia con el monarca aragonés durante julio, en Valencia, sobre la base de que jamás Sicilia sería devuelta. La advertencia era seria, porque desde el principio los plenipotenciarios pontificios se negaron a tratar con los sicilianos ${ }^{164}$. Sicilia, simplemente, debía volver a 1282. Ese mes de julio, Nicolás IV comisionó a su capellán, maese Raimundo, para exigir a Jaime I la inmediata devolución de Sicilia.

Jaime I buscando evitar un peligroso aislamiento sorprendió con una ambiciosa propuesta: devolvería todos los derechos y bienes eclesiásticos (nunca el Reino) e iría a la Cruzada, pero el Papa respetaría sus derechos regios a Sicilia, le concedería los privilegios de un cruzado (fin de los anatemas), ampararía una tregua de Sicilia con la Iglesia, Francia, Castilla, Jaime II y Carlos II por diez años (es decir, le admite en las negociaciones) y consentiría el matrimonio de Alfonso III con $\mathrm{D}^{\mathrm{a}}$ Leonor de Inglaterra (guiño a la confederación dinástica) ${ }^{165}$. El 10 de agosto, en una bula, Nicolás IV declaraba a Jaime I perseguidor de la Iglesia. No había acuerdo.

Realmente inquieto, Jaime I inició una diplomacia ofensiva desestabilizadora. Génova se había alineado interesadamente con el Papado y exigía la inmediata retirada catalanoaragonesa de Sicilia ${ }^{166}$, por lo que el 3 de julio Jaime I amplió los privilegios genoveses en Sicilia ${ }^{167}$, pero además encargaba a Bertrán de Canellas asentar su matrimonio con

159 Alfonso III, el 6 de junio, les solicita acudan a Gascuña o área de Tolosa y da seguro a sus emisarios para hacer más ágil la comunicación, ACA, Reg. 73, f. 85 r y v.

160 ACA, Reg. 73, f. 84 v.

161 ACA, Reg. 73, f. $82 \mathrm{v}$.

162 ACA, Reg. 82 , f. 45 v- 46 .

163 Sendas cartas, de plenos poderes (en ACA, Pergaminos de Alfonso II) y proyecto matrimonial, pub. LA MANTIA, Códice diplomático dei..., obr. cit., nº 196 a 200, pp. 459-474.

164 Cit. J. ZURITA, Anales, obr. cit., p. 407.

165 Pub. LA MANTIA, Códice diplomático dei..., obr. cit., nº 209, pp. 493-495.

166 Para contrarrestar esta ofensiva el 10 de junio de 1290 Alfonso III revalidó la alianza con Pisa. Cit. L. KLÜPFEL, Die Aüssere politik..., obr. cit., pp. 70-71.

167 Pub. LA MANTIA, Códice diplomático dei.., obr. cit., n² 203, pp. 480-481. 
$D^{a}$ Guillerma de Montcada ${ }^{168}$, reciente heredera de los estados de Bearn, que amenazaban Aragón, Francia e Inglaterra. Desde el verano, además, bombeó víveres ${ }^{169}$ y dinero ${ }^{170}$ a Aragón, forzando la expresa gratitud de Alfonso $1 \mathrm{II}^{171}$. Pese a todo, a través de Conrado Lanza, acreditado el 10 de agosto ${ }^{172}$, el monarca aragonés debió advertir a su hermano sobre su endeble posición diplomática frente a la obcecación pontificia.

De hecho, Alfonso III rediseñaba la política catalano-aragonesa en el Mediterráneo, como si la cuestión siciliana estuviera superada. A la alianza con Granada, unió las intentonas en Marruecos, una embajada a Tremecén en julio de 1290 y el 1 de diciembre otra encargada a Bernardo de Bellvis en Arborea (Córcega) ${ }^{173}$ y Túnez. En Egipto, Berenguer de Sant Liceri y Ramón Alamán gestionaban una alianza ${ }^{174}$, que se concretó en septiembre de 1290. Por fin, el 13 de noviembre Alfonso III confirmaba a Jaime I que el mes próximo íniciaría los preliminares de una paz de la que Sicilia era excluida ${ }^{175}$. Oficiosamente la realidad debía ser otra, porque el aragonés enviaba a Artal de Azlor para una información reservada a Jaime I.

Muy satisfecho, el 18 de noviembre el Papa absolvía de anatemas a Aragón ${ }^{176}$, mientras exigía sumisión a Jaime I y el día 20 renovaba el proceso contra él. Nada parecía detener la paz. El 8 de diciembre de 1290 emisarios aragoneses iniciaban sesiones preparatorias en Montpellier con los plenipotenciarios pontificios, mientras Alfonso III reunía Cortes en Barcelona para someter las condiciones de la paz y elaboración de un tratado. En enero de 1291 disponía una brillante comitiva para la negociación ${ }^{177}$.

\subsection{El Tratado de Tarascón-Brignoles (1291)}

La seguridad de una paz exacerbó la oposición de Génova al impulso marítimo catalán. En enero de 1291 Alfonso III recibía una embajada genovesa ${ }^{178}$ poco

168 ACA, Pergaminos de Alfonso II, n 370. Pub. LA MANTIA, Ibídem, n²02, pp. 477-479.

169 Órdenes de entrega de partidas de trigo siciliano a Artaldo de Bastida o Berenguer de Finestres, el 10 de junio, ACA, Reg. 82, f. 57; reconocimiento de deuda, el 7 de agosto, de Alfonso III por 21.000 sueldos reales de Valencia por transporte de trigo siciliano, ACA, Reg. 82, f. 60; el 15 de noviembre solicitó Alfonso III permiso de exportación de trigo a Jaime I, ACA, Reg. 81, f. 207.

170 Alfonso III confirma el envío de un emisario para recibir cierto dinero de Jaime 1, como acusa recibo de 400 onzas de oro del siciliano a través de Cerviá de Riera, ACA, Reg. 85, f. 23.

171 En carta del 18 de septiembre, ACA, Reg. 73, f. 88v-89.

172 ACA, Reg. 73 , f. 86 v. Similar acreditación se extendía significativamente ante $D^{\text {a }}$ Constanza, Roger de Lauria y Giovanni Prócida.

173 ACA, Reg. 73, f. 90 v.

174 El 8 de agosto el rey les reconocía una deuda por esta legación, ACA, Reg. 73, f. 71v-72, aceptando su relación de gastos el 24 de septiembre de 1290, ACA, Reg. 82, f. 71 v.

175 ACA, Reg. 73, f. 89 v.

176 Así lo recordaba ese día Alfonso IIl a los arzobispos de Zaragoza y Tarragona, como al obispo de Barcelona, ACA, Reg. 81 , f. 208 r y v.

177 ACA, Reg. 84, f. 2.

178 Dirigida por Francisco de Camilla al que el rey concede un seguro el 15 de enero, ACA, Reg. 84 , f. 12. El 30 de enero ordenaba costear caballos para Francisco y Damián de Camilla, junto con León Spínola, ACA, Reg. 82, f. 12. 
tranquilizadora, porque el 12 de enero excusaba el retraso de envío de embajadores ante los plenipotenciarios pontificios ${ }^{179}$. En sospechosa coincidencia una legación granadina ofrecía mediar entre Alfonso III y Castilla, propuesta muy conveniente para Génova pues trastocaba la estrategia de Alfonso III en el Estrecho de Gibraltar. en este instante, la embajada genovesa exponía la voluntad de su República: Jaime I debía abandonar Sicilia ${ }^{180}$.

Alfonso III buscó conjurar el peligro. El 11 de enero entregaba un memorial a Abraham Abenamies ofreciendo a Granada apoyo logístico y militar aragonés, advirtiendo su aproximación a Marruecos (potencial enemigo nazarí) y reputando inútil la mediación con Castilla por ser Sancho IV un rey taimado y estar próxima la paz de Aragón con ta Santa Sede y Francia ${ }^{181}$. El 23 de enero, de otro lado, expresaba a Génova el deseo de una alianza ${ }^{182}$ y el 30 de enero concedía especiales privilegios mercantiles a genoveses.

Sin embargo, el tiempo corría en contra de los intereses aragoneses, por lo que Alfonso III precipitó el tratado. El 27 de enero dio credenciales a sus representantes y el día 28 concedió seguro a todo emisario que comunicase las partes signatarias del tratado $^{183}$. Las sesiones se iniciaban en Montpellier el 2 de febrero, continuaron en Tarascón y culminaron en Brignoles, buscando aislamiento de presiones, el 19 de febrero.

Fue un tratado prolijo en se deseo de sentenciar todos los contenciosos de la Cristiandad y así fomentar un espíritu cruzado. Alfonso III veía reconocida su legitimidad a cambio de reconocerse vasallo de la Iglesia (pagaría un censo, acudiría con fuerzas militares a Roma en la Navidad de 1291) y acudir a la Cruzada en junio de 1292. Esta generosidad pontificia se compensaba respecto a Sicilia: Alfonso III liberaría todos los rehenes angevinos, pactaría una paz bilateral con Carlos II, cercenaría toda ayuda a Sicilia, instando a Jaime I a abandonar el trono siciliano, incluso le desalojaría al volver de la Cruzada. Por si cabían dudas, Génova ofrecía a Carlos II 70 galeras para recuperar Sicilia ${ }^{184}$.

En realidad los designios del Alfonso III eran otros a los que rubricó. En lo formal manifestó ser un escrupuloso cumplidor del tratado: firmó la paz con Carlos II en abril de 1291, pergeñando una colaboración mediterránea, pues el aragonés utilizó su influencia sobre los givelinos italianos y secundaba los intereses angevinos en Hungría en favor de Carlos II $^{185}$, mientras el angevino reconocía el statu quo de Mallorca (posesión aragonesa) y mediaría ante Génova ${ }^{186}$, crecientemente anticatalana; el 28 de

179 ACA, Reg. 73, f. 91.

180 ACA, Reg. 73, f. 92v-93.

181 Acreditación en ACA, Reg. 84, f. 10 v; el memorial, ACA, Reg. 73, f. 91v-92.

182 ACA, Reg. 73 , f. 92 r y v.

183 ACA, Reg. 84, f. 19.

184 Cit. J. ZURITA, Anales, obr. cit., p. 413.

185 ACA, Reg. 73, f. 98.

186 Animado, Alfonso III dispone que la preceptiva embajada que iría a Roma, se detendría en Génova, ACA, Reg. 73, f. 97 v. 
marzo ordenó a bailes y vegueres de Cataluña y Valencia interrumpir la navegación hacia Sicilia y Calabria, incluso a los justicias valencianos la exportación de pez; envió al abad de Poblet para exponer sus terminantes compromisos por la paz de Tarascón.

Lo cierto es que en los cálculos de Alfonso III no entraba el completo abandono de Sicilia ${ }^{187}$. Así lo debió expresar secretamente a Jaime I a través de Gisbert de Castellet, que acompañó al abad de Poblet y lo reiteró mediante Bernat de Ginesbret en una nueva embajada el 22 de abrilir8. Al parecer, Alfonso III preparaba una complicada triquiñuela: el tratado le obligaba a no apoyar a su hermano, pero no estipulaba que Sicilia debiera ser devuelta a los Anjou. Así las cosas, ¿quién sería el "tenente" siciliano de la Santa Sede? Alfonso III recomendaba a su hermano preparar una nave de trigo a Roma, donde la legación aragonesa obtendría resultados convenientes.

\section{LA HERENCIA ALFONSINA DE D. JAIME}

Clausuraba así, satisfactoriamente, las Vísperas Sicilianas Alfonso III disponiéndose entonces a desarrollar su propio programa político, libre de la herencia paterna. Apenas esbozó unas líneas, firmes sin embargo.

$1^{\circ}$ Retención de Baleares mediante un complejo contencioso, amparado en el derecho feudal y de conquista.

$2^{\circ}$ Reconocer la soberanía pontificia (nunca angevina) sobre Sicilia. La posesión se reservaría a testaferros aragoneses en la calidad que determinasen futuras negociaciones con la Santa Sede.

30 Reforzar los protectorados en Magreb, plataforma de dominio mediterráneo y paso a Gibraltar. El 15 de mayo se rubricaba un nuevo tratado con Tremecén ${ }^{189}$ y en junio con Túnez.

$4^{\circ}$ Consolidar una berroqueña alianza anglo-aragonesa ${ }^{190}$, alternativa al eje franco-castellano surgido en Bayona, aquel 1291.

5을 Subvertir el «orden peninsular» castellanista, que confirmaba la debilidad aragonesa en la península. La anexión de Albarracín y conspiraciones en Molina, señoríos de una Sistema Ibérico que asfixiaba a Aragón, así como la cesión del Reino de Murcia (puertos hacia Gibraltar) por D. Alfonso de la Cerda, son pruebas fehacientes.

La rápida defunción de Alfonso III el 18 de junio de 1291, dejó en proyecto su programa. La suerte de D. Jaime dio un vuelco espectacular al convertirse en el nuevo monarca aragonés. Si llegó con una mentalidad siciliana, la fuerza de los hechos hizo que adoptase la perspectiva catalano-aragonesa de Alfonso III respecto a Sicilia y que asimilase las líneas políticas que su hermano esbozara. Jaime II dio sentido al reinado de Alfonso III.

187 Pub. L. KLÜPFEL, Die Aüssere politik..., obr. cit,, oำ 8, pp. 159-160.

188 ACA, Reg. 82, f. 183 v.

189 ACA, Reg. 82, f. 186 v.

190 Cit. J. ZURITA, Anales, obr. cit., p. 416. 